\title{
Tendencias de movilidad social en la Argentina de las dos últimas décadas: 1995-2010*
}

\author{
Jesica Lorena Pla \\ José Javier Rodríguez de la Fuente \\ Universidad de Buenos Aires. Facultad de Ciencias Sociales. \\ Instituto de Investigaciones Gino Germani \\ jpla@sociales.uba.ar; jrodriguez@conicet.gov.ar
}

Recepción: 28-09-2014

Aceptación: 21-04-2016

\section{Resumen}

En este artículo, se muestran las principales tendencias de movilidad social en la Región Metropolitana de Buenos Aires, durante el período 1995-2010, por medio de tasas absolutas y tasas relativas. Se utilizaron datos primarios provenientes de cuatro encuestas diferentes, realizadas por el Centro de Estudios de Opinión Pública (CEDOP), de la Facultad de Ciencias Sociales (UBA), en 1995, durante el periodo 2003-2004, en el año 2007 y durante el lapso 2009-2010, respectivamente.

Los principales resultados a los que se arribó describen que, entre la década de 1990 y finales del año 2000, las tasas absolutas de movilidad social disminuyeron. Particularmente, se observa, durante los años noventa, que la clase trabajadora (manual) asume un papel distribuidor por todas las clases sociales. Estas tendencias se explican por efecto del proceso de apertura económica, descentralización, desindustrialización y flexibilización de

* Las reflexiones y los resultados que aquí se presentan forman parte de un proceso de investigación mayor desarrollado en el marco de dos proyectos ANPyCT FONCYT. En primer lugar, el Proyecto PICT 2011-2189: Tendencias y transformaciones en la estructura social: El impacto de los procesos de movilidad social en los horizontes de consumo, y, en segundo lugar, más recientemente, el PICT 2013-2709: ¿Una nueva fragmentación social?: Socialización/ riesgos, movilidad social y representaciones subjetivas sobre la política. RMBA 2009-2014. Asimismo, algunos resultados aquí trabajados han sido parte de la tesis doctoral de Jésica Pla: Trayectorias inter-generacionales de clase y marcos de certidumbre social: La desigualdad social desde la perspectiva de la movilidad. Área Metropolitana de Buenos Aires. 2003-2011, presentada en abril de 2013 en la Facultad de Ciencias Sociales, Universidad de Buenos Aires, dirigida por el Dr. Eduardo Chávez Molina y codirigida por el Dr. Agustín Salvia. 
la economía. Por el contrario, durante la década de 2000, se observa una mayor herencia dentro de dicha clase social, como efecto contrario a la década anterior, en un contexto de recomposición del mercado de trabajo, de aumento de la demanda de empleo y de revitalización de sectores como la industria, el transporte y la construcción.

Desde el análisis de la movilidad relativa, en cambio, observamos que el patrón de movilidad tendió a hacerse más rígido. Es decir, sin considerar los cambios estructurales, el origen social tiene mayor peso en el destino de una persona.

Palabras clave: estratificación social; reproducción social; clases sociales; estructura social; fluidez social

\begin{abstract}
Social Mobility Paths in Argentina in the Last Two Decades: 1995-2010
This article characterizes the main social mobility trends in the metropolitan area of Buenos Aires during the period 1995-2011. Absolute and relative rates of social mobility are analyzed based on mobility tables, odds ratios and the study of social flux patterns. The data sources are made up of primary information from four different surveys conducted by the Center for Public Opinion Studies (CEDOP) of the Social Sciences Faculty at the University of Buenos Aires in 1995, 2003-2004, 2007 and 2009-2010, respectively. The main results show that the absolute rates of social mobility declined in the 1990s and late 2000, with a strong tendency towards the reproduction of the skilled working class (severe towards the end of the period), but differing from the previous decade where it had a distributor role across all social classes due to the effect of the opening process, decentralization, deindustrialization and flexibilization of the economy. The analysis of relative mobility indicates that the pattern of stratification was not stable and there is a trend towards greater rigidity.
\end{abstract}

Keywords: social stratification; social reproduction; social class; social structure; social fluidity

\author{
Sumario \\ 1. Introducción 5. Resultados \\ 2. ¿El estatus o las relaciones de clase? \\ 6. Movilidad y reproducción. \\ 3. Apuntes metodológicos \\ 4. Argentina: cambios estructurales \\ e impactos en los procesos \\ de movilidad social \\ Dos décadas complejas \\ Referencias bibliográficas \\ Anexo
}

\title{
1. Introducción
}

Las sociedades modernas se organizan a partir de una división fundamental entre propietarios y no propietarios de los medios de producción. La división de la sociedad en clases, entonces, es el resultado de un proceso histórico, en el cual el trabajo se constituye en el principio estructurador de las relaciones sociales (Postone, 2006).

Diversos han sido los abordajes de las temáticas que se derivan de esa división, particularmente de los procesos de estratificación y, a la par, de la 
movilidad social, tanto desde lo teórico (Sorokin, 1925; Parsons, 1954; Glass, 1954; Goodman, 1965; Yasuda, 1964; Erikson y Goldthorpe, 1992; Wright, 1994; Bertaux, 1994; Bourdieu, 2002, entre otros) ${ }^{1}$ como por medio de la realización de estudios empíricos ${ }^{2}$.

En este artículo, analizamos las tendencias de movilidad social que han caracterizado a la Región Metropolitana de Buenos Aires ${ }^{3}$ durante el período 1995-2011, identificando el modo en que los cambios estructurales por los cuales atravesó Argentina en ese periodo tuvieron, o no, impacto sobre las mismas. Lo realizamos a partir de una estrategia metodológica cuantitativa, con base en datos primarios de diferentes encuestas realizadas por el Centro de Estudios de Opinión Pública (CEDOP) de la Facultad de Ciencias Sociales (UBA), en los años 1995, 2003-2004, 2007 y 2009-2010, respectivamente ${ }^{4}$.

\section{2. ¿El estatus o las relaciones de clase?}

De manera sintética, dos son las perspectivas teóricas desde las cuales se han abordado los procesos de estratificación y movilidad social. Por un lado, la perspectiva funcionalista, caracterizada por una visión gradacional de los estratos sociales. Por otro lado, la perspectiva relacional, que engloba (no sin tensiones ni dificultades) los abordajes marxistas y weberianos (Pla, 2013b).

Desde la perspectiva funcionalista (cuyo origen podría marcarse en Sorokin (1925), pasando por Davis y Moore (1945) y culminando en Parsons (1954), entre otros), la sociedad es concebida como un sistema en el cual el proceso de estratificación se explica por la motivación individual ("esfuerzo») de los actores por ocupar los diferentes puestos de la estructura social. Dicha motivación es inducida por la existencia de sistemas de valores compartidos. Los mismos emanan del hecho de que, dado que los puestos de la estructura social satisfacen necesidades diferenciales en su importancia para el sistema social, las «recompensas» que tienen asociadas cada uno de ellos es diferente y desigual.

El corolario de esta mirada se sustenta en un concepto de equidad basado en la igualdad de oportunidades (de origen). La movilidad social se constituye como el componente principal del proceso de estratificación. Frente a la igualdad de oportunidades en el origen, la movilidad social visibiliza el esfuerzo de los actores de moverse por la estructura social, y la posición ocupada, el logro

1. Señala Cachón Rodríguez (1989) que el debate sobre la movilidad social estuvo hegemonizado por la perspectiva funcionalista sobre la estratificación en las dos décadas posteriores a la posguerra. Recién en la década de 1970, este debate se abre al campo neoweberiano y neomarxista, es decir, desde una perspectiva de clases. En la misma línea, nos extendemos en el artículo (Pla, 2013b).

2. Por otro lado, cabe mencionar que, en el punto 4 de este artículo, se reseñan los principales abordajes empíricos que se han hecho en Argentina en relación con la temática del artículo. Allí se presentan como antecedentes, pero también para caracterizar los procesos históricos por los cuales ha atravesado el país.

3. La misma comprende a la Ciudad de Buenos Aires y los 24 partidos que conforman el Gran Buenos Aires (INDEC, 2003).

4. Se trata de muestras estratificadas, multietápicas y aleatorias en todas las etapas del muestreo. 
del mismo. Así, la desigualdad social aparece como la consecuencia del proceso de estratificación en el cual los individuos obtienen las «recompensas» que derivan del puesto que lograron, motivación individual mediante.

Este abordaje funcionalista se corresponde con un paradigma del orden, caracterizado por una orientación consensualista que acentúa la integración y el equilibrio frente al conflicto de intereses (Feito Alonso, 1995).

La perspectiva relacional, en cambio, se caracteriza por centrar el conflicto y el poder como ejes para pensar la estructura social. Al decir «relacional», nos referimos a que las distintas clases participan de un modo de producción que se basa en la propiedad privada, en el trabajo, y en las «relaciones» que entre esos conceptos se establecen. Una posición no es necesariamente «más» que la otra (Erikson y Goldthorpe, 1992), son distintas en tanto tienen una participación diferente en el sistema de producción, aunque esa posición diferenciada es desigual, pues unos solo disponen de su trabajo para vivir y otros tienen la propiedad privada de los medios de producción y se valen del trabajo de otros para ponerlos en funcionamiento y obtener una ganancia.

Todas las definiciones de clase social que se estructuran en torno a esta idea, entre las que pueden ubicarse las concepciones marxistas y weberianas, coinciden en que las estructuras sociales desiguales conforman a su vez estructuras de intereses (Feito Alonso, 1995: 31). Tanto las concepción marxista como la weberiana reconocen a la esfera económica como el espacio de constitución de las clases sociales, como una esfera determinante del orden social: para unos, las clases son el resultado de las relaciones de producción, para otros, de las oportunidades de los sujetos de valorar en el mercado los recursos que poseen (Longhi, 2005: 106).

De manera sintética, consideramos que son cuatro los supuestos que debe seguir un abordaje de los procesos de movilidad social que parta desde una perspectiva relacional:

1. La realidad no es transparente, sino que la sociología hace que algo sea visible (interpretación).

2. La sociedad debe ser comprendida en su heterogeneidad.

3. Los hechos sociales básicos del campo de la movilidad social afectan fundamentalmente a grupos sociales como tales, cuya condición varía en la estructura de posiciones sociales.

4. Diversos mecanismos interrelacionados determinan la posición de los grupos sociales y de los individuos en su interior, así como sus posibilidades de modificar históricamente su posición (familia, escuela, mercado de trabajo, Estado y otros).

Cabe destacar, entonces, que partimos desde esta última perspectiva y que, al hablar de descensos o ascensos, no nos estamos refiriendo a posiciones de jerarquía o prestigio, sino de movimientos entre posiciones mejor ubicadas, y otras peor ubicadas, con respecto a esa desigualdad inherente al modo de producción capitalista. 


\section{Apuntes metodológicos}

El universo de estudio se delimitó entre personas ocupadas que tenían entre 25 y 65 años al momento de realizar cada uno de los sondeos. Esta delimitación permite captar a individuos que, con mayor probabilidad, se encuentran en una etapa de madurez ocupacional (Echeverría Zabalza, 1999), es decir, una edad en la que normalmente los individuos han recorrido la mayor parte de su trayectoria laboral.

A partir de los datos socioocupacionales que facilitan los encuestados (ocupación, categoría ocupacional, sector de actividad, tamaño del establecimiento en el que trabaja, etc.), los agrupamos dentro de una categoría de clase social. Pero, como en los estudios de movilidad social también es necesario conocer el origen social de los individuos, para ello, se utilizan los datos retrospectivos que ofrece el encuestado sobre la posición del principal sostén del hogar (PSHO) en el cual habitaba a la edad de 16 años 5 . De este modo, se pone en relación a la condición de clase del encuestado con la del origen.

Teniendo en cuenta los supuestos que debe seguir el análisis de los procesos de movilidad social que parta desde una perspectiva relacional, mencionados anteriormente, utilizamos un esquema de clases que dé cuenta de los mismos. El esquema de clases propuesto por Torrado $(1992)^{6}$ permite caracterizar la especificidad de las relaciones de clase en América Latina, al dar cuenta de una característica propia de esta región: la existencia de un sistema de producción definido por la articulación de relaciones de producción capitalistas y relaciones mercantiles simples (mercado heterogéneo y segmentado), propias de economías que se han insertado de manera periférica en el sistema mundo (Chávez Molina, Pla y Molina Derteano, 2011: 180). Señala Torrado (1998: 234) que son las relaciones de producción las que constituyen el criterio para la delimitación de los subconjuntos de agentes sociales que ocupan una posición análoga, o sea, para la determinación de la forma que asume en la sociedad la división social del trabajo.

El nomenclador de la condición socioocupacional (CSO) (Torrado, 1992, 1998) se compone de doce estratos construidos a partir de las siguientes variables: ocupación, categoría de ocupación, rama de actividad, sector de actividad y tamaño del establecimiento. Para nuestro análisis, los estratos del CSO fueron reagrupados en categorías que permiten visualizar diferencias de clases y condi-

5. El conjunto de datos para el PSHO no necesariamente nos permite inferir sobre las estructuras sociales de periodos determinados, pues estos no fueron extraídos de una muestra aleatoria, sino que son producto de una técnica retrospectiva. El ciclo vital en el que se encuentre el encuestado, la edad, la edad del PSHO al momento en que él nació, entre los principales factores, no permite inferir que los marginales de origen sean representativos de un tiempo histórico determinado.

6. Este esquema fue diseñado originalmente por De Ipola y Torrado (1976). Los autores desarrollaron un esquema teórico basado en la noción de división social del trabajo en la sociedad capitalista latinoamericana. Distinguen relaciones de producción determinantes, la explotación y las relaciones de producción determinadas, de propiedad, de posesión, de control técnico y de detentación, que dan lugar a capas sociales. 
Esquema 1. Nomenclador de la condición socioocupacional, estratos y clase social

\begin{tabular}{|c|c|c|c|c|c|}
\hline & $\begin{array}{l}\text { Nomenclador de la } \\
\text { ndición socioocupacional }\end{array}$ & \multicolumn{2}{|r|}{ Estratos (Torrado) } & \multicolumn{2}{|r|}{ Reagrupamiento (propio) } \\
\hline 1 & Directores de empresas & 1 & Empresarios directores & \multirow{5}{*}{1} & \multirow{5}{*}{ Clase media alta } \\
\hline 2 & $\begin{array}{l}\text { Profesionales en función } \\
\text { específica asalariados }\end{array}$ & \multirow[t]{2}{*}{2} & \multirow{2}{*}{$\begin{array}{l}\text { Profesionales en función } \\
\text { específica }\end{array}$} & & \\
\hline 3 & $\begin{array}{l}\text { Profesionales en función } \\
\text { específica autónomos }\end{array}$ & & & & \\
\hline 4 & $\begin{array}{l}\text { Propietarios de pequeñas } \\
\text { empresas }\end{array}$ & \multirow{2}{*}{3} & \multirow{2}{*}{ Propietarios } & & \\
\hline 5 & $\begin{array}{l}\text { Pequeños productores } \\
\text { autónomos }\end{array}$ & & & & \\
\hline 6 & $\begin{array}{l}\text { Cuadros de técnicos } \\
\text { y asimilados }\end{array}$ & 4 & Técnicos & 2 & Clase media \\
\hline 7 & $\begin{array}{l}\text { Empleados administrativos } \\
\text { y comerciantes }\end{array}$ & 5 & $\begin{array}{l}\text { Empleados y } \\
\text { administradores }\end{array}$ & 3 & Clase media rutinaria \\
\hline 8 & $\begin{array}{l}\text { Trabajadores } \\
\text { especializados autónomos }\end{array}$ & 6 & Trabajadores & 4 & Clase trabajadora \\
\hline 9 & Obreros calificados & & & & \\
\hline 10 & Obreros no calificados & 7 & Trabajadores & 5 & \\
\hline 11 & Peones autónomos & & & 5 & $\begin{array}{l}\text { Clase trabajadora baja } \\
\text { y marginal }\end{array}$ \\
\hline 12 & Empleados domésticos & 8 & Empleados domésticos & & \\
\hline
\end{tabular}

Fuente: elaboración propia en base a Torrado (1992, 1998), Boado (2008) y Pérez (2011).

ciones de vida, siguiendo el criterio original de Torrado y aquellos encontrados en Boado Martínez (2008), Pérez (2011), Sacco (2011a, 2011b) y Pla (2013a). Los tradicionales análisis de movilidad se basan en una tabla de doble entra$\mathrm{da}$, en la cual se ponen en relación las posiciones de origen con las posiciones de destino (Sorokin, 1925; Lipset y Bendix, 1963; Goodman, 1965). Muchos y extensos han sido los debates sobre la pertinencia o no del análisis de las tasas absolutas para evidenciar los cambios en las tendencias de movilidad social ${ }^{7}$. En este artículo, reconocemos que, si bien este tipo de abordajes tiene limitaciones metodológicas, las mismas no son inherentes a la técnica, sino a la pertinencia de las respuestas que se pueden dar con las mismas. Los debates se han centrado en que un análisis de este tipo no permite comprender la desigualdad endógena a una sociedad, porque las mismas cambian, sus estructuras se transforman y las personas pueden verse "forzadas» a ocupar diferentes tipos de empleos. Pero este tipo de análisis es pertinente cuando el objetivo es dar cuenta de los cambios sustantivos y estructurales de la sociedad (Carabaña, 1999; Fachelli y López Roldán, 2012a). Es decir, los cambios estructurales existen y, retomando la clásica y, no por simple, iluminadora formula de Marx, diremos que los

7. De hecho, los debates sobre las técnicas específicas para «medir» la movilidad son los debates que caracterizan a este campo de estudio en el periodo de posguerra. 
trabajadores, «libres», en su doble sentido, se ven obligados a vender su fuerza de trabajo donde la misma sea requerida: el trabajo no por sufrir incontables y trascendentes mutaciones ha dejado de ser el estructurador de las relaciones sociales (Postone, 2006; Danani y Grassi, 2009).

El análisis de la movilidad social absoluta nos permitirá encontrar respuesta a la siguiente pregunta: jen qué proporción se movieron las personas en cada uno de los años y hacia dónde lo hicieron con respecto a la posición social del principal sostén del hogar de origen (PSHO)? El análisis temporal enfoca de manera más integral las tendencias que describen a una sociedad, al hacerlo en términos comparativos. Las personas no solamente "se mueven», sino que también «se comparan». No es lo mismo una sociedad que mantiene sus índices de movilidad durante décadas, sin modificarse, que otra en la cual varían (Carabaña, 1999). Tampoco es lo mismo una sociedad que mantiene índices estables pero cambian en su composición: puede ser que la misma proporción de sujetos ocupe una clase social diferente a la del PSHO, pero la misma puede ser más "cercana o lejana", puede ofrecer menores o mayores recompensas económicas y estar asociada a condiciones diferenciales de vida.

La muestra sobre la que se trabaja, como bien se indicó, se ha acotado a la Región Metropolitana de Buenos Aires (RMBA), ya que es de ese nivel geográfico de donde disponemos de datos comparables. En la actualidad (según datos del Censo de Población del INDEC de 2010), la Región Metropolitana de Buenos Aires ocupa una superficie total de $2.590 \mathrm{Km}^{2}$ y reúne 12,8 millones de habitantes, lo cual representa una concentración cercana al 32\% de la población total del país, a la vez que produce alrededor del $40 \%$ del PIB nacional. Debido a esta destacada participación económico-demográfica, más una serie de factores históricos, esta área metropolitana se ha convertido en el centro productivo, comercial, financiero y político más importante de Argentina. El 23\% de toda la población del área reside en la capital (2,9 millones de habitantes), mientras que el $77 \%$ lo hace en el Conurbano bonaerense $(9,9$ millones de habitantes). Asimismo, al interior del Conurbano, la población se distribuye aproximadamente en un 33\% en la Zona Sur, un 32\% en la Zona Norte y el restante 35\% en la Zona Oeste. La Ciudad Autónoma de Buenos Aires está compuesta por 48 barrios o unidades territoriales. En general, la Zona Norte concentra los barrios de un nivel socioeconómico más elevado y que se encuentran en mejores condiciones socioambientales, mientras que los barrios de la Zona Sur son, en general, los más rezagados.

\section{Argentina: cambios estructurales e impactos en los procesos de movilidad social}

Analizar los procesos de estructuración de clases en el marco de los análisis de movilidad social implica, necesariamente, revisar en clave histórica las características que estos procesos han seguido. De este modo, y refiriéndonos al caso argentino, presentamos algunos lineamientos que ubican al problema al que abordamos históricamente, en pos de analizarlo luego, a la 
luz de los cambios estructurales de las últimas dos décadas, con sus rupturas y continuidades.

Desde 1880 hasta 1930, en la Argentina primó un modelo fundamentado en la exportación de bienes primarios (agrícolas) (Basualdo, 2006). La dinámica de crecimiento era "expansiva», basada en la circulación de la renta diferencial ${ }^{8}$, e impulsó la emergencia de un temprano desarrollo comercial e industrial urbano. Ese crecimiento tuvo como correlato la consolidación de una clase obrera urbana y de un sector de clase media. La inmigración masiva desde Europa desempeñó un rol fundamental en dicho proceso?.

La formación de la clase obrera dio lugar a un periodo de tensiones y conflictos ${ }^{10}$ que delimitaron el "proceso constituyente» de la sociedad y del Estado en la Argentina, así como la formación de clases sociales y la imposición de un orden para esos elementos (Danani y Hintze, 2011b: 21). Los primeros intentos de seguridad social son emergentes de ese proceso. Tanto las políticas represivas como la política laboral ${ }^{11}$, tuvieron como objetivo mantener el orden social.

El sector de clase media se conformó como resultado de un proceso de movilidad intrageneracional ascendente de los inmigrantes (Germani, $1963 b^{12}$ ). Llach (1997) sostiene que ese proceso de ascenso y consolidación, en un contexto de crecimiento, dio lugar a un «exceso» de aspiraciones modernizantes, en términos de ingresos y consumos.

8. Entendida como la ganancia extraordinaria que se produce, por ejemplo, entre dos campos, ante la misma inversión de capital y trabajo, debido a la diferente productividad de la tierra y su fertilidad natural. Históricamente, Argentina ha tenido una renta diferencial debido a la alta fertilidad de las amplias llanuras que caracterizan a su territorio. Esto ha demarcado también que se inserte en el sistema mundo como productora de bienes primarios. La propiedad de la tierra se da por grandes latifundios concentrados, por lo cual la dinámica de crecimiento no se basa en la renta que esta produce para la gran mayoría, sino por la circulación de la misma, particularmente en el ámbito urbano. Por la misma razón en Argentina ha primado la población urbana (más del $80 \%$ desde comienzos del siglo xx) por encima de la rural.

9. Debido al régimen de propiedad de la tierra y/o el régimen de labor que funcionaba en la Argentina de comienzos de siglo, para los inmigrantes fue difícil afincarse en zonas rurales, y lo hicieron en la ciudad de Buenos Aires. El número de habitantes de la ciudad pasó de representar un $15 \%$ a un $30 \%$ de la población total del país entre 1870 y 1914 . La mitad de sus habitantes eran personas nacidas en el extranjero que, por sus edades promedio, aportaban una proporción aún mayor de la fuerza de trabajo local (Schvarzer, 1977: 3).

10. En 1914, la clase obrera fabril conformaba aproximadamente el $25 \%$ de la población económicamente activa (PEA) de Buenos Aires. Si bien en aquel entonces el salario era elevado (en relación con los que se obtenían en Europa), los trabajadores se veían sometidos a malas y severas condiciones de labor y a la imposibilidad de acceder a ciertos bienes y servicios, en particular, la vivienda (Schvarzer, 1977: 3).

11. En particular, referidas a previsión y accidentes de trabajo.

12. Torrado (1992) señala que esta interpretación sobre el ascenso de los inmigrantes se sustenta en un supuesto: ellos tenían, en sus países de origen, posiciones inferiores a las que aquí alcanzaron. Este supuesto se asienta en las características que tuvo la población inmigrante, en general proveniente de estratos sociales muy rezagados, aunque empíricamente no fuera medido. 
La crisis mundial de los años treinta produjo un giro en el proceso histórico: la fuerte caída de la demanda mundial de bienes agropecuarios generó un derrumbe de las exportaciones y afectó el acceso al crédito internacional. Las políticas implementadas (barreras arancelarias, subsidios a la producción, otorgamiento de créditos, etc.) favorecieron un proceso de industrialización por sustitución de importaciones que se afianzó como eje de la economía con la llegada al Gobierno de Perón en el año 1945.

Este nuevo contexto dio lugar a un giro en los procesos de movilidad social: si el modelo anterior se caracterizaba por el auge de la movilidad social a lo largo de la vida de una persona, el nuevo modelo abre las oportunidades de movilidad social entre generaciones. Las tasas de movilidad social ascendentes se mantuvieron similares a las del periodo anterior, confirmando una alta movilidad desde niveles populares hasta niveles medios y altos (Germani, 1963b: 332). Sin embargo, si anteriormente los que «ascendían» eran los inmigrantes, particularmente europeos, durante este periodo, los inmigrantes internos o de países limítrofes se ubicaron en los estratos inferiores, «empujando» a los nacidos en la ciudad a las posiciones medias (Germani, 1963b: 341). Este proceso se correlaciona también con un incremento de la importancia de la educación como canal de ascenso social hacia las posiciones de clase media asalariada. Sin embargo, la clase obrera estuvo más relegada del uso de la educación formal como canal de movilidad social ascendente (Torrado, 1992: 323). Para los inmigrantes internos, la movilidad se explicó particularmente por el pasaje de empleos no calificados rurales a empleos como trabajador manual industrial, en general calificados.

Contemporáneo a Germani, el enfoque de Rubinstein (1973) arroja algunos resultados disímiles, señalando que el grado de movilidad en toda la historia argentina es relativamente bajo, exceptuando periodos excepcionales como la crisis de 1930 (Rubinstein, 1973: 329). Es decir, la industrialización intensificó la movilidad, pero sin alterar sustancialmente los sistemas de relaciones entre las clases sociales. Aquí radica entonces la diferencia interpretativa. Germani analiza los procesos de movilidad social en términos de cambios en la ocupación. Rubinstein, en cambio, los estudia desde las propiedades que definirían a una clase (variables laborales, ingresos, educación y vivienda). Las interpretaciones, por tanto, no necesariamente son excluyentes, pues es posible que haya movilidad en términos de ocupación en la estructura social, pero no en las condiciones de vida, que reflejan desigualdades estructurales entre las clases sociales.

El trabajo de Beccaria (1978) aporta elementos para conocer qué pasó en términos de estratificación social y movilidad entre principios de la década de 1960 y finales de la misma. Este periodo se caracteriza por la consolidación de un nuevo bloque de poder en el que la burguesía industrial nacional se articula con el capital extranjero, especialmente con grandes empresas transnacionales norteamericanas, en pos de una industrialización sustitutiva de bienes intermedios y de consumo durable. En términos sociales, este nuevo bloque de poder tiene el efecto de reemplazar trabajo de clase obrera asalariada y 
autónoma (destruyendo pequeños y medianos establecimientos industriales) por la creación de trabajo asalariado de clase media (administrativos y técnicos) en establecimientos de mayor envergadura. En este periodo, se distingue una tasa de movilidad elevada, compuesta por movimientos descendentes y ascendentes en proporción similar, de corta distancia (es decir, entre posiciones contiguas) y altos niveles de autorreclutamiento entre los estratos superiores. La destrucción de puestos de trabajo por cuenta propia empujó a los hijos de este tipo de trabajadores a buscar otras ocupaciones, en muchos casos más bajas, pero también habilitó la consolidación de microempresas relacionadas con el núcleo dinámico de la economía. Es decir, la reducción del cuentapropismo no significó un descenso en la proporción de miembros de la clase media, porque la tendencia fue equilibrada por otros movimientos (Beccaria, 1978: 616).

Los procesos de concentración y centralización del capital que se dieron desde los años sesenta anunciaron las características que marcarían la estrategia que se inició en 1976, interpretación que se extiende hacia el campo políticocultural y los mecanismos de integración (Torrado, 1992).

El modelo de industrialización por sustitución de importaciones se sostuvo en base a un régimen de acumulación que tenía al mercado interno, el consumo y el pleno empleo como ejes de su modelo. Pero el período abierto en 1976 significó un cambio en el patrón de acumulación sustitutivo de importaciones vigente hasta entonces (Pucciarelli, 2004). Por medio de una dictadura militar, se aplicaron medidas, entre las que se incluyó el terrorismo de estado, para desarticular el poder de la clase obrera en ascenso y la distribución del ingreso relativamente equitativa. En términos económicos, se tradujo en la apertura comercial, la desindustrialización y reforma del sistema financiero.

Los procesos derivados de la implementación de una política económica de esas características abrieron paso a una crisis externa y fiscal sin precedentes, que hizo de los años ochenta una década signada por un escenario de desequilibrios estructurales que culminó en la hiperinflación del año 1989. La salida de la misma se logró a principios de los años noventa por medio de un programa de convertibilidad y un paquete de reformas estructurales (Gerchunoff y Torre, 1996). A nivel de la estructura ocupacional, se observa una rigidización en las condiciones del mercado laboral, en la cual el incremento de las oportunidades de trabajos calificados en servicios favorece principalmente a quienes ocupaban posiciones cercanas, como mínimo técnicas o administrativas (Jorrat, 1987).

La estrategia aperturista encontró sus límites en la crisis económica, política y social del período 2001-2002, cuando comenzó un nuevo modelo caracterizado por una conjunción entre el cambio de precios relativos a favor de los sectores productores de bienes comerciables y un conjunto de políticas de intervención estatal orientadas a recuperar los equilibrios macroeconómicos básicos (Damill y Frenkel, 2006; Pérez, 2011; Lavopa, 2007 y 2008; Azpiazu y Schorr, 2008; Kosacoff, 2010). El resultado fue una recuperación económica, un incremento de la demanda agregada de empleo y una mejora de los indicadores sociales en general (CENDA, 2010), aunque con la persistencia de ciertos "claroscuros» (Kessler, 2011) en lo que respecta a indicadores de desigualdad persistentes. 
A su vez, desde la dictadura militar, se abrió un proceso de valorización financiera (Basualdo, 2006) que significó un incremento constante de la deuda pública, que se constituyó como uno de los condicionantes para el crecimiento social. Este proceso tendió a revertirse en la nueva fase sociopolítica posterior a la convertibilidad. Mientras que, hasta el año 2004, la deuda externa significaba un porcentaje superior del PIB, en el año 2005, tras la renegociación y el canje de deuda pública, el endeudamiento externo se redujo considerablemente, pasando a representar en los años siguientes alrededor del 50\% (CIFRA-CTA, 2011: 8).

La reestructuración de la deuda pública debe ser analizada en conjunto con la novedad de un tipo de cambio competitivo poco volátil. Este proceso no solo implica una mejora automática en el resultado fiscal (porque la participación de los bienes y servicios transables en la recaudación es mayor que en el gasto público), sino que el financiamiento de la inversión se origina - como consecuencia de esta combinación de factores- totalmente en el ahorro nacional. Este hecho modera la volatilidad y elimina los costos del sudden stop ('estancamiento repentino'). A esto se suma la mejora de los términos del intercambio exterior. La caída de los precios de importación y el incremento de los precios de exportación hacen aumentar el poder de compra del ahorro y mejorar la inversión, haciéndola menos volátil a los cambios en la economía mundial, lo cual marca una diferencia sustancial con el período precedente (Arceo et al., 2008: 67).

En el escenario de crecimiento, la industria se posicionó como uno de los principales sectores impulsores del proceso de recuperación económica. El PIB de la industria manufacturera, que decreció a mediados de la década de 1990, tendió a incrementarse de manera constante a partir del año 2002, llegando a los niveles de la década de 1990 en el 2004 y superándolos a partir de entonces. Ahora bien, comparar su crecimiento con el de otras ramas nos aporta un panorama más detallado de esta primacía de la recuperación con fuerte impronta de dicho sector. Durante el período 2002-2006, la industria manufacturera creció un 24,2\% (acumulativo anual), porcentaje similar al total del sector de bienes, mientras que el sector servicios se contrajo alrededor de un 20\% (Arceo et al., 2008: 69). Estas tendencias son marcadamente opuestas a las que se visibilizaron como resultado de la década.

En este contexto, el interés por la problemática de la estratificación y la movilidad social se ha renovado en nuestro país a lo largo de la última década. Los estudios de Jorrat (2005, 2007, 2008, 2011a y 2011b), además de los anteriormente citados, han hecho mayor énfasis en analizar las tendencias de movilidad social en clave comparativa internacional, para lo cual ha utilizado esquemas de clases sociales aceptados internacionalmente. Kessler y Espinoza (2007), por su parte, evidencian, hacia fines de la década de 1990, cambios cualitativos en los procesos de movilidad social, caracterizados por el ascenso en la escala de prestigio ocupacional, pero también por el descenso en las recompensas sociales asociadas a estas.

Benza (2010) ha analizado la particularidad de los procesos de movilidad desde y hacia las clases medias, mientras Dalle (2009, 2011a y 2011b) ha 
dirigido el foco hacia el estudio de los canales de ascenso social desde la clase trabajadora, en un periodo de larga duración que «vuelve» sobre los análisis de Germani y llega hasta el año 2005. Ambos autores usan escalas propias sobre los microdatos de CEDOP UBA que les resultan útiles para sus objetivos de investigación. Gómez Rojas y Riveiro (2013a y 2013b) indagan acerca de las diferencias en las probabilidades de movilidad social según el género. Salvia y Quartulli (2011), en cambio, se valen de las mismas técnicas de movilidad social, pero las utilizan para analizar tendencias en el mercado de trabajo, por lo cual sus clasificaciones adquieren una raigambre teórica diferente. Lo mismo ocurre con los trabajos de Chávez Molina y Gutiérrez Ageitos (2009) o de Pla y Chávez Molina (2010a, 2010b), al analizar tendencias de movilidad en un sector marginal de la población. Pla (2013a) analiza la relación entre los procesos de movilidad social, las políticas sociales y la conformación de marcos de certidumbre e incertidumbre con respecto a la propia vida y a las generaciones por venir. Pla y Rodríguez de la Fuente (2013) analizan algunas hipótesis sobre las características que adquiere la movilidad social intergeneracional en la década de 2000 para la Argentina ${ }^{13}$.

\section{Resultados}

\subsection{Análisis de los patrones de movilidad absoluta}

Son los procesos antes descritos los que deben servir de marco para interpretar los patrones de movilidad social y las trayectorias que los mismos dibujan. En primer lugar, en el cuadro 1, se presenta la configuración de la estructura de clases de acuerdo con los años en los que se han efectuado los relevamientos. Si bien se presentan algunas oscilaciones, hay tendencias que caracterizan la transformación de la estructura en el período abordado. Mientras que la clase trabajadora marginal se mantiene relativamente estable en participación total, la clase trabajadora calificada pasa de estar representada por un $27 \%$ a un $41 \%$ de la población, entre los años 1995-2010, consistente en el proceso de recomposición industrial comentado en el apartado anterior. Por su parte, la clase media rutinaria, compuesta por ocupaciones principalmente administrativas y del rubro de servicios, se mantuvo estable representando entre un $17 \%$ y un $21 \%$ de la población estudiada. En contraposición, la clase media - referida en nuestro estudio principalmente a aquellas posiciones "técnicas»— evidenció un retroceso en su participación, pasando de un $18 \%$ en 1995 a un $11 \%$ en 2010. Finalmente, la clase media alta, aunque no en forma lineal, también redujo su participación relativa en la estructura de clases, al pasar de un $25 \%$ a un $14 \%$.

Los índices absolutos de movilidad social expresan la movilidad que se observa en cada año de la encuesta. Es una mirada que pone en juego la rela-

13. Finalmente, gran parte del debate en torno a esta problemática que se ha renovado a partir de los últimos años en algunos ámbitos académicos del país y de la región pueden hallarse en el número 24 de la revista Lavboratorio. Ver http://publicaciones.sociales.uba.ar/index. php/lavboratorio/issue/view/28/showToc 
Cuadro 1. Estructura de clases sociales. RMBA. 1995, 2003-2004, 2007, 2009-2010

\begin{tabular}{|c|c|c|c|c|c|c|c|c|}
\hline \multirow{2}{*}{$\begin{array}{l}\text { Clase social } \\
\text { del encuestado }\end{array}$} & \multicolumn{2}{|l|}{1995} & \multicolumn{2}{|c|}{ 2003-2004 } & \multicolumn{2}{|l|}{2007} & \multicolumn{2}{|c|}{$2009-2010$} \\
\hline & Frecuencia & $\%$ & Frecuencia & $\%$ & Frecuencia & $\%$ & Frecuencia & $\%$ \\
\hline I. Clase media alta & 216 & $25 \%$ & 110 & $19 \%$ & 137 & $21 \%$ & 54 & $14 \%$ \\
\hline II. Clase media & 152 & $18 \%$ & 67 & $12 \%$ & 98 & $15 \%$ & 40 & $11 \%$ \\
\hline $\begin{array}{l}\text { III. Clase media } \\
\text { rutinaria }\end{array}$ & 143 & $17 \%$ & 123 & $21 \%$ & 121 & $18 \%$ & 73 & $20 \%$ \\
\hline $\begin{array}{l}\text { IV. Clase trabajadora } \\
\text { calificada }\end{array}$ & 235 & $27 \%$ & 198 & $34 \%$ & 222 & $33 \%$ & 152 & $41 \%$ \\
\hline $\begin{array}{l}\text { IV. Clase trabajadora } \\
\text { marginal }\end{array}$ & 116 & $13 \%$ & 80 & $14 \%$ & 90 & $13 \%$ & 54 & $14 \%$ \\
\hline Total & 862 & $100 \%$ & 578 & $100 \%$ & 668 & $100 \%$ & 373 & $100 \%$ \\
\hline
\end{tabular}

Base: encuestados ocupados entre 25 y 65 años.

Fuente: elaboración propia en base a la encuesta CEDOP.

ción entre origen y destino en cada uno de los años que tomamos de referencia (cada relevamiento, siendo estos cuatro). Luego, comparamos los índices entre dichos años, para dar cuenta de variaciones en los mismos.

Por un lado, en la década de 1990, la apertura y el proceso de desindustrialización, a la par que una terciarización de la economía, podrían explicar el hecho (cuadro 1) que, en 1995, más personas se encontraban en una clase social diferente a la del PSHO, con respecto al año 2007, tendencia decreciente que se confirma en la serie de los cuatro años. Ahora bien, esto no nos permite hacer ninguna inferencia sobre "a dónde fueron" esos hijos, en uno y otro año, ni por qué motivo se «movieron» menos en la década inmediatamente posterior.

Pero aquí entra en juego la idea de trayectoria, pues no solo importa cuántos se movieron, sino también cuánto se movieron quienes efectivamente lo hicieron y qué distancia trazaron. En 1995, la movilidad de corta distancia, a posiciones cercanas de clase, explicaba el $48 \%$ de la movilidad y, como consecuencia, la de larga distancia explicaba el 52\%. Es decir, era casi similar, pero con una leve prevalencia de la larga. Esta tendencia se revierte en la década de 2000, con mayor énfasis hacia el final de la misma.

Aún en el terreno descriptivo, estas apreciaciones nos permiten empezar a caracterizar el periodo actual, pero también a encontrar sus límites en términos de estas construcciones metodológicas. Digamos, por ahora, que la existencia de una menor proporción de movilidad y de una mayor preeminencia de la de corto alcance nos podría estar indicando la existencia de límites difusos entre clases aledañas.

Cabe, entonces, preguntarse lo siguiente: ¡cómo se distribuyeron quienes compartían un mismo origen social? La respuesta nos permite analizar el grado de herencia o de movilidad al interior de cada origen social, es decir que lo que se comparan son las filas de la tabla, las cuales, conceptualmente, representan la distribución de cada clase según el origen social del individuo ${ }^{14}$.

14. Nos referimos a los porcentajes de salida (outflows). 
Cuadro 2. Índices absolutos de movilidad social. RMBA. 1995, 2003-2004, 2007, 2009-2010

\begin{tabular}{|c|c|c|c|c|c|c|c|c|}
\hline \multirow[b]{2}{*}{ Índices } & \multicolumn{2}{|c|}{1995} & \multicolumn{2}{|c|}{ 2003-2004 } & \multicolumn{2}{|c|}{2007} & \multicolumn{2}{|c|}{$2009-2010$} \\
\hline & Índice & $\%$ & Índice & $\%$ & Índice & $\%$ & Índice & $\%$ \\
\hline Movilidad & \multicolumn{2}{|c|}{$66,8 \%$} & \multicolumn{2}{|c|}{$63,7 \%$} & \multicolumn{2}{|c|}{$58,8 \%$} & \multicolumn{2}{|c|}{$57,4 \%$} \\
\hline Movilidad ascendente & $38,5 \%$ & $\underline{58 \%}$ & $37,7 \%$ & $\underline{59 \%}$ & $36,7 \%$ & $\underline{62 \%}$ & $33,5 \%$ & $\underline{58 \%}$ \\
\hline Movilidad descendente & $28,3 \%$ & $\underline{42 \%}$ & $26,0 \%$ & $\underline{41 \%}$ & $22,2 \%$ & $\underline{38 \%}$ & $23,9 \%$ & $\underline{42 \%}$ \\
\hline Movilidad de corta distancia & $32,3 \%$ & $48 \%$ & $34,3 \%$ & $54 \%$ & $31,6 \%$ & $54 \%$ & $36,5 \%$ & $64 \%$ \\
\hline Movilidad de larga distancia & $34,6 \%$ & $52 \%$ & $29,4 \%$ & $46 \%$ & $27,2 \%$ & $46 \%$ & $20,9 \%$ & $36 \%$ \\
\hline
\end{tabular}

Base: encuestados ocupados entre 25 y 65 años (1995: $n=862 ; 2003-2004: n=578 ; 2007: n=668$; 2009-2010: $n=373$ ).

Fuente: elaboración propia en base a la encuesta CEDOP.

En primer lugar, cabe señalar que la clase media asalariada de rutina o de baja calificación mantiene su peso relativo a lo largo de los quince años que analizamos, mientras que la clase trabajadora calificada aumenta en proporción mucho mayor al resto de las clases. Como puede verse, este cambio en la estructura social hacia una mayor demanda de puestos manuales calificados tiene su correlato en una mayor herencia para esta clase, es decir, en menores probabilidades de movilidad social o de cambio de posición con respecto al hogar de origen (en 2007, un 46\% de aquellos con orígenes en la clase trabajadora calificada reproducen su condición social, mientras que en 1995 solo lo hace un $35 \%$ de estos).

El incremento de las personas ocupadas en posiciones de clase trabajadora calificada asalariada ${ }^{15}$ podría estar explicado por los efectos que tuvieron la devaluación de la moneda luego de la crisis del año 2001-2002 y el mayor impulso y dinamismo del mercado interno que mostraron esos procesos en los años posteriores sobre las dinámicas del mercado de trabajo (tendencia creciente de la tasa de ocupación, decreciente la de desocupación y mayor dinamismo del sector industrial por encima del sector servicios). Cabe destacar que dichos procesos tienen efectos al conformar estructuras del mercado de trabajo, y demandas concretas, diferenciales, y estos procesos de cambio estructural afectan a los índices y a las tendencias de movilidad social, cuando esta es abordada desde el enfoque de la movilidad absoluta (y no así cuando se hace desde la movilidad relativa, cuando justamente se busca «aislar» ese efecto).

Ahora bien, ¿cuál es la relación entre estos movimientos y el origen social? En el año 2007, es mayor la reproducción de la clase media alta, pero también se observa entre la clase media rutinaria: mientras, en 1995, casi cuatro de cada diez personas de clase media alta de origen ocupaban la misma clase, esa proporción aumentó al 50\% en el año 2007. Otro modo de ver la reproducción o la herencia entre clases medias altas es considerando "la esquina superior izquierda», es decir, tomando las clases I y II en su conjunto: mientras, en 1995,

15. Usando el esquema de Torrado que nosotros aplicamos aquí, Sacco (2011a) encuentra evidencias en el mismo sentido de un incremento de la clase obrera asalariada. 
la herencia entre esas clases era del 50\%, en el 2007 se incrementa al 70\%. Este primer acercamiento nos estaría abonando la hipótesis de la clausura o del cierre social de la clase superior ${ }^{16}$ (Goldthorpe, 1987; Espinoza, 2002; Jorrat, 2000).

La otra pregunta que se puede responder desde el análisis de la movilidad social absoluta es: ¿cómo se compone cada clase social?, es decir, ¿de dónde «vienen» quienes comparten una misma posición de clase? La respuesta nos permite comparar si el origen social de las personas se diferencia cuando se pertenece a una u otra clase, razón por la cual se trabaja con cada una de las columnas y se comparan entre $s^{17}$.

El examen de las tasas de entrada, es decir, de la composición de las clases sociales (cuadro 3), nos muestra que, en 1995, todas fueron reclutadas de la clase trabajadora calificada en una proporción superior al 35\%. Si los análisis de movilidad absoluta relacionan los procesos de movilidad con los de cambio estructural, este dato estaría visualizando de manera clara el proceso de ruptura de la sociedad salarial anteriormente mencionada, cambios que produjeron un desmembramiento de la clase trabajadora y un desperdigamiento de esos «hijos» por toda la estructura social. En el caso de los trabajadores que ascendieron a puestos no manuales, de clase media, podrían ser los casos de movilidad espuria que señalaban Kessler y Espinoza (2007).

En el año 2007, las tasas de herencia no fueron iguales en todas las clases sociales. La mayor proporción se observa en la clase trabajadora calificada. En el caso de la clase media alta, la proporción de un tercio disminuyó a un quinto (un $37 \%$ contra un 22\%), mientras que es mayor el porcentaje que presenta la clase media y, como se mencionó anteriormente, el del reclutamiento en la misma clase. Si, en 1995, el 35\% de la clase media estaba formado por personas con origen de clase trabajadora calificada, en 2007, ese porcentaje asciende a casi el 50\%. Este cambio evidencia un nuevo canal de movilidad ascendente desde la clase trabajadora, probablemente sustentado en el rol de la educación, particularmente terciaria (Dalle, 2011a).

Con respecto a la clase media rutinaria, de empleados administrativos y de servicios, tanto en el año 1995 como en el año 2007, la mitad provenía de orígenes de clase trabajadora, en particular, de la mejor posicionada en el interior de la misma.

Analicemos ahora las personas con origen clase media rutinaria y trabajadora calificada, quienes se distribuyeron de forma similar en los dos periodos considerados. Sin embargo, la clase trabajadora calificada tuvo mayor reproducción en 2007, ya que casi la mitad de las personas de ese origen tienen la misma clase del PSHO, mientras que, en 1995, la proporción era de alrededor de un tercio (observando los porcentajes de salida). Este proceso podría estar explicando los

16. Esta hipótesis, que ganó aceptación en los estudios de movilidad social de posguerra, explicaba que la clase alta «reclutaba» a la gran mayoría de sus miembros internamente o bien de estratos cercanos (lo cual generaba, consecuentemente, una movilidad de corta distancia), ello da apoyo a la idea de que existe una barrera entre la clase superior y el resto de las clases.

17. Porcentaje de entrada (inflows). 
Cuadro 3. Tabla de movilidad, porcentajes de salida (outflows). RMBA. 1995, 2003-2004, 2007, 2009-2010

\begin{tabular}{|c|c|c|c|c|c|c|c|}
\hline \multirow{2}{*}{\multicolumn{2}{|c|}{ Clase del PSHO }} & \multicolumn{6}{|c|}{ Clase del encuestado } \\
\hline & & $\begin{array}{c}\text { I. Clase } \\
\text { media alta }\end{array}$ & $\begin{array}{l}\text { II. Clase } \\
\text { media }\end{array}$ & $\begin{array}{c}\text { III. Clase } \\
\text { media rutinaria }\end{array}$ & $\begin{array}{c}\text { IV. Clase } \\
\text { trabajadora } \\
\text { calificada }\end{array}$ & $\begin{array}{l}\text { IV. Clase } \\
\text { trabajadora } \\
\text { marginal }\end{array}$ & Total \\
\hline \multirow[t]{4}{*}{ I } & 1995 & $36 \%$ & $21 \%$ & $14 \%$ & $20 \%$ & $8 \%$ & $100 \%$ \\
\hline & 2003-2004 & $37 \%$ & $11 \%$ & $24 \%$ & $25 \%$ & $3 \%$ & $100 \%$ \\
\hline & 2007 & $51 \%$ & $14 \%$ & $19 \%$ & $11 \%$ & $5 \%$ & $100 \%$ \\
\hline & 2009-2010 & $43 \%$ & $17 \%$ & $11 \%$ & $24 \%$ & $4 \%$ & $100 \%$ \\
\hline \multirow[t]{4}{*}{ II } & 1995 & $26 \%$ & $33 \%$ & $28 \%$ & $11 \%$ & $2 \%$ & $100 \%$ \\
\hline & 2003-2004 & $40 \%$ & $24 \%$ & $20 \%$ & $8 \%$ & $8 \%$ & $100 \%$ \\
\hline & 2007 & $44 \%$ & $24 \%$ & $12 \%$ & $12 \%$ & $8 \%$ & $100 \%$ \\
\hline & $2009-2010$ & $22 \%$ & $30 \%$ & $13 \%$ & $22 \%$ & $13 \%$ & $100 \%$ \\
\hline \multirow[t]{4}{*}{ III } & 1995 & $32 \%$ & $26 \%$ & $18 \%$ & $19 \%$ & $4 \%$ & $100 \%$ \\
\hline & 2003-2004 & $16 \%$ & $21 \%$ & $34 \%$ & $24 \%$ & $5 \%$ & $100 \%$ \\
\hline & 2007 & $30 \%$ & $21 \%$ & $25 \%$ & $17 \%$ & $6 \%$ & $100 \%$ \\
\hline & $2009-2010$ & $22 \%$ & $19 \%$ & $28 \%$ & $26 \%$ & $5 \%$ & $100 \%$ \\
\hline \multirow[t]{4}{*}{ IV } & 1995 & $20 \%$ & $13 \%$ & $17 \%$ & $35 \%$ & $15 \%$ & $100 \%$ \\
\hline & 2003-2004 & $13 \%$ & $10 \%$ & $17 \%$ & $42 \%$ & $18 \%$ & $100 \%$ \\
\hline & 2007 & $8 \%$ & $13 \%$ & $16 \%$ & $46 \%$ & $16 \%$ & $100 \%$ \\
\hline & 2009-2010 & $7 \%$ & $7 \%$ & $20 \%$ & $50 \%$ & $16 \%$ & $100 \%$ \\
\hline \multirow[t]{4}{*}{ V } & 1995 & $14 \%$ & $11 \%$ & $11 \%$ & $31 \%$ & $34 \%$ & $100 \%$ \\
\hline & 2003-2004 & $14 \%$ & $5 \%$ & $18 \%$ & $40 \%$ & $24 \%$ & $100 \%$ \\
\hline & 2007 & $10 \%$ & $8 \%$ & $16 \%$ & $35 \%$ & $31 \%$ & $100 \%$ \\
\hline & $2009-2010$ & $3 \%$ & $0 \%$ & $17 \%$ & $47 \%$ & $33 \%$ & $100 \%$ \\
\hline
\end{tabular}

Base: encuestados ocupados entre 25 y 65 años (1995: $n=862 ; 2003-2004: n=578 ; 2007: n=668$; 2009-2010: $n=373$ ).

Fuente: elaboración propia en base a la encuesta CEDOP.

menores niveles de movilidad observados en el año 2007, aunque un análisis exhaustivo debería considerar que, desde el año 2003 hasta la actualidad, la clase trabajadora calificada ha mejorado sus ingresos y sus condiciones de trabajo, lo cual ha sido producto, entre otras cosas, de una revitalización de los sindicatos (Palomino, 2007), mientras la clase media no calificada ha mantenido posiciones más estancas en lo relativo a ingresos. Esta tendencia también es observable en el cuadro 3, donde las tasas de entrada indican que la mayor parte de la clase trabajadora calificada (un 76\%) en el 2007 se reclutó de la misma clase, mientras, en 1995, ese porcentaje era de alrededor del 60\%. Si, para su análisis de la década de 1990, Kessler y Espinoza (2007), en una localidad del Conurbano bonaerense, observaban procesos de movilidad de corto alcance entre los orígenes manuales y el sector no manual de servicios, una primera mirada nos estaría indicando que esas tendencias podrían estar mutando juntamente a un modelo de desarrollo estatal con mayor intervención directa sobre la economía, los salarios y la distribución secundaria (Panigo y Neffa, 2009). 
Cuadro 4. Tabla de movilidad, porcentajes de entrada (inflows). RMBA. 1995, 2003-2004, 2007, 2009-2010

\begin{tabular}{|c|c|c|c|c|c|c|c|}
\hline \multirow{2}{*}{\multicolumn{2}{|c|}{ Clase del PSHO }} & \multicolumn{6}{|c|}{ Clase del encuestado } \\
\hline & & \multirow{2}{*}{$\begin{array}{c}\begin{array}{c}\text { I. Clase } \\
\text { media alta }\end{array} \\
37 \%\end{array}$} & \multirow{2}{*}{$\begin{array}{c}\text { II. Clase } \\
\text { media } \\
30 \%\end{array}$} & \multirow{2}{*}{$\begin{array}{c}\text { III. Clase } \\
\text { media rutinaria } \\
22 \%\end{array}$} & \multirow{2}{*}{$\begin{array}{c}\text { IV. Clase } \\
\text { trabajadora } \\
\text { calificada }\end{array}$} & \multirow{2}{*}{$\begin{array}{c}\text { IV. Clase } \\
\text { trabajadora } \\
\text { marginal }\end{array}$} & \multirow{2}{*}{$\begin{array}{r}\text { Total } \\
25 \%\end{array}$} \\
\hline 1 & 1995 & & & & & & \\
\hline & 2003-2004 & $35 \%$ & $16 \%$ & $20 \%$ & $13 \%$ & $4 \%$ & $18 \%$ \\
\hline & 2007 & $39 \%$ & $14 \%$ & $17 \%$ & $5 \%$ & $6 \%$ & $15 \%$ \\
\hline & $2009-2010$ & $37 \%$ & $20 \%$ & $7 \%$ & $7 \%$ & $4 \%$ & $12 \%$ \\
\hline \multirow[t]{4}{*}{ II } & 1995 & $7 \%$ & $13 \%$ & $11 \%$ & $3 \%$ & $1 \%$ & $7 \%$ \\
\hline & $2003-2004$ & $9 \%$ & $9 \%$ & $4 \%$ & $1 \%$ & $3 \%$ & $4 \%$ \\
\hline & 2007 & $8 \%$ & $6 \%$ & $2 \%$ & $1 \%$ & $2 \%$ & $4 \%$ \\
\hline & $2009-2010$ & $9 \%$ & $18 \%$ & $4 \%$ & $3 \%$ & $6 \%$ & $6 \%$ \\
\hline \multirow[t]{4}{*}{ III } & 1995 & $14 \%$ & $16 \%$ & $12 \%$ & $8 \%$ & $3 \%$ & $11 \%$ \\
\hline & 2003-2004 & $15 \%$ & $30 \%$ & $27 \%$ & $12 \%$ & $6 \%$ & $17 \%$ \\
\hline & 2007 & $28 \%$ & $27 \%$ & $26 \%$ & $10 \%$ & $9 \%$ & $19 \%$ \\
\hline & 2009-2010 & $24 \%$ & $28 \%$ & $22 \%$ & $10 \%$ & $6 \%$ & $16 \%$ \\
\hline \multirow[t]{4}{*}{ IV } & 1995 & $37 \%$ & $35 \%$ & $48 \%$ & $59 \%$ & $53 \%$ & $47 \%$ \\
\hline & 2003-2004 & $31 \%$ & $39 \%$ & $37 \%$ & $57 \%$ & $61 \%$ & $46 \%$ \\
\hline & 2007 & $22 \%$ & $49 \%$ & $48 \%$ & $76 \%$ & $67 \%$ & $55 \%$ \\
\hline & $2009-2010$ & $28 \%$ & $35 \%$ & $59 \%$ & $68 \%$ & $63 \%$ & $56 \%$ \\
\hline \multirow[t]{4}{*}{$\mathrm{V}$} & 1995 & $6 \%$ & $7 \%$ & $7 \%$ & $12 \%$ & $28 \%$ & $11 \%$ \\
\hline & 2003-2004 & $11 \%$ & $6 \%$ & $13 \%$ & $18 \%$ & $26 \%$ & $15 \%$ \\
\hline & 2007 & $4 \%$ & $4 \%$ & $7 \%$ & $8 \%$ & $17 \%$ & $7 \%$ \\
\hline & 2009-2010 & $2 \%$ & $0 \%$ & $8 \%$ & $11 \%$ & $22 \%$ & $10 \%$ \\
\hline \multirow[t]{4}{*}{ Total } & 1995 & $100 \%$ & $100 \%$ & $100 \%$ & $100 \%$ & $100 \%$ & $100 \%$ \\
\hline & 2003-2004 & $100 \%$ & $100 \%$ & $100 \%$ & $100 \%$ & $100 \%$ & $100 \%$ \\
\hline & 2007 & $100 \%$ & $100 \%$ & $100 \%$ & $100 \%$ & $100 \%$ & $100 \%$ \\
\hline & 2009-2010 & $100 \%$ & $100 \%$ & $100 \%$ & $100 \%$ & $100 \%$ & $100 \%$ \\
\hline
\end{tabular}

Base: encuestados ocupados entre 25 y 65 años (1995: $n=862 ; 2003-2004: n=578 ; 2007: n=668$; 2009-2010: $n=373$ ).

Fuente: elaboración propia en base a la encuesta CEDOP.

\subsection{Probabilidades relativas de movilidad social.} Las trayectorias de clases en la dinámica temporal

En el apartado anterior, dimos cuenta de las potencialidades, pero también de los límites del análisis de movilidad «absoluta». En particular, apuntamos el hecho de que, al comparar dos distribuciones con marginales diferentes, los cambios entre una u otra posición son, inevitablemente, forzados por los cambios en la estructura social que representan esos márgenes diferentes que determinan que unas clases dejen de tener peso, otras pasen a tener más peso y las personas se muevan por efecto de esas variaciones. No se explica nada acerca de la movilidad relativa, aquella que nos indicaría el grado en que el 
Cuadro 5. Probabilidades relativas de desplazarse hacia la clase más alta, la clase media y la clase más baja. RMBA. 1995, 2003-2004, 2007, 2009-2010

\begin{tabular}{lcccc}
\hline & \multicolumn{4}{c}{ Probabilidad de alcanzar a la clase más alta } \\
\cline { 2 - 5 } Clase del PSH0 & 1995 & $2003-2004$ & 2007 & $2009-2010$ \\
\hline Clase media alta & 1,00 & 1,00 & 1,00 & 1,00 \\
Clase media & 0,62 & 1,12 & 0,74 & 0,36 \\
Clase media rutinaria & 0,83 & 0,33 & 0,41 & 0,38 \\
Clase trabajadora calificada & 0,43 & 0,25 & 0,08 & 0,10 \\
Clase trabajadora marginal & 0,28 & 0,27 & 0,11 & 0,04 \\
\hline & \multicolumn{3}{c}{ Probabilidad de alcanzar a la clase media rutinaria } \\
\hline Clase media alta & 0,75 & 0,60 & 0,71 & 0,32 \\
Clase media & 1,74 & 0,48 & 0,40 & 0,39 \\
Clase media rutinaria & 1,00 & 1,00 & 1,00 & 1,00 \\
Clase trabajadora calificada & 0,93 & 0,39 & 0,55 & 0,68 \\
Clase trabajadora marginal & 0,53 & 0,43 & 0,57 & 0,53 \\
\hline & \multicolumn{5}{c}{ Probabilidad de alcanzar a la clase más baja } \\
\hline Clase media alta & 0,18 & 0,10 & 0,12 & 0,09 \\
Clase media & 0,03 & 0,28 & 0,20 & 0,30 \\
Clase media rutinaria & 0,09 & 0,17 & 0,15 & 0,11 \\
Clase trabajadora calificada & 0,35 & 0,72 & 0,45 & 0,39 \\
Clase trabajadora marginal & 1,00 & 1,00 & 1,00 & 1,00 \\
\hline Clases medias & Probabilidad relativa de pasar de la clase trabajadora a la clase media \\
\hline Clases trabajadoras & 1,00 & 1,00 & 1,00 & 1,00 \\
\hline
\end{tabular}

Fuente: elaboración propia en base a la encuesta CEDOP.

origen social afecta a las oportunidades de acceder a las diferentes posiciones, comparando relativamente entre diferentes personas con origen social distinto.

Un modo de analizar las oportunidades relativas de movilidad social es estableciendo un punto de referencia, de comparación, siempre en razón de las oportunidades de los originarios de una determinada clase social. De este modo, podemos ver, de manera gráfica, los cambios en las condiciones de competencia en el sistema de movilidad social, con independencia de oscilaciones económicas (Cortés y Escobar Latapí, 2005: 158), lo cual nos permite responder estos interrogantes: ¿las oportunidades de acceder a la clase más alta se encuentran distribuidas de forma igualitaria? ¿Y a la clase más baja? Para llevar adelante dicho propósito, apelaremos a las razones de momios o "de oportunidades» (odd's ratios), a través de las cuales se compara la probabilidad que tiene, por ejemplo, un individuo con orígenes de clase media en acceder a la clase media alta, en contraposición con otro de orígenes de clase media alta de reproducir su situación.

En el cuadro 5, presentamos este ejercicio tomando como comparación cuatro grupos de interés relevante: la clase media alta, la clase media rutinaria y la clase trabajadora marginal, en todos los casos, de igual origen social. 
Adicionalmente, se compara el total de la clase trabajadora con el total de la clase media (agregando los tres grupos que la componen), con el objeto de medir cambios en la probabilidad relativa de traspasar la barrera existente entre «manual» $\mathrm{y}$ «no manual».

Las oportunidades relativas de alcanzar a la clase más alta disminuyen a medida que el origen social es más desventajoso. Esta tendencia se hace más evidente en los periodos más recientes: mientras que, en 1995, las personas ocupadas originariamente de clase trabajadora calificada tenían la mitad de las probabilidades que las personas de clase media alta de llegar a esta última clase, en 2007, esa proporción disminuyó a casi el 100\%. También disminuyeron las probabilidades relativas de la clase media rutinaria, es decir que se agrandó la brecha entre orígenes de clase al interior de la clase media, de modo que, en la actualidad, son "más cercanas» la clase media técnica y la alta. Si bien hay más movilidad, como observamos anteriormente, la clase media también se dualiza, y las posiciones menos aventajadas van «quedando más lejos» de las posiciones mejor ubicadas en la estructura social. A su vez, las clases medias altas redujeron sus oportunidades relativas de descenso social.

Con respecto a la probabilidad de acceder a la clase media rutinaria, según el origen social, si bien para el conjunto de la clase trabajadora disminuye constantemente ( 0,29 a 0,15 en 1995 y 2007, respectivamente), la probabilidad de las personas de origen de clase trabajadora de acceder a la clase media rutinaria es negativa en todo el periodo: en 1995, quienes tenían un origen de clase trabajadora calificada poseían casi las mismas probabilidades que quienes tenían un origen de clase media rutinaria de pertenecer a esta clase social, proporción que, para 2007, era del 0,55. Sin embargo, en este caso, creemos importante destacar que, entre 2003-2004 y 2007, la misma aumenta un 40\% (de 0,39 al ya mencionado 0,55$)$ y, para el 2009-2010, ascendió aún más $(0,68)$, tendencia que es menos pronunciada en la clase trabajadora marginal. En nuestra interpretación, estos movimientos no son menores, en un contexto de crecimiento económico y mayor regulación estatal, estos cambios en el patrón de fluidez social indican que, con independencia del stock o de los puestos disponibles, las personas con orígenes en la clase trabajadora calificada comienzan a tener oportunidades relativas de acceder a la clase media de rutina similares a quienes ocupan esa posición habiendo reproducido la misma. Es decir, las distancias entre estos estratos tienden a hacerse más próximas, siendo este uno de los únicos indicios de mayor fluidez en la última década.

\subsection{Análisis de la estabilidad del régimen de fluidez social}

Confirmando las tendencias anteriormente señaladas, ponemos en juego el análisis del régimen de fluidez. La tesis de la «fluidez constante» fue formulada por Erikson y Goldthorpe (1992), quienes sostienen que las desigualdades de herencia en relación con la movilidad intergeneracional se mantienen estables a lo largo de los años, para cualquier sociedad medianamente industrializada, con predominio familiar nuclear y del mercado de trabajo (Boado, 2008). 
Cuadro 6. Ajuste de los modelos temporales de fluidez constante y cambio uniforme. RMBA. 1995, 2003-2004, 2007, 2009-2010

\begin{tabular}{|c|c|c|c|c|c|c|}
\hline \multicolumn{7}{|c|}{ Modelo de fluidez constante $(1995,2003-2004,2007,2009-2010)$} \\
\hline & G2 & gl & SIG. & Seudo R2 & $\mathrm{BIC}$ & ID \\
\hline Independencia condicional (PO) (PD) & 468,60 & 64 & 0,00 & - & $-31,90$ & $17,2 \%$ \\
\hline Fluidez constante (PO) (PD) (OD) & 82,2 & 48 & 0,00 & $82,5 \%$ & $-293,1$ & $6,5 \%$ \\
\hline $\begin{array}{l}\text { Efecto multiplicativo uniforme por } \\
\text { cohortes (unidiff) (PO) (PD) (OD) }\end{array}$ & 149,6 & 60 & 0,00 & $68,1 \%$ & $-319,7$ & $9,0 \%$ \\
\hline \multicolumn{7}{|c|}{ Parámetros de periodos } \\
\hline 1995 & \multicolumn{2}{|c|}{ 2003-2004 } & \multicolumn{2}{|c|}{2007} & \multicolumn{2}{|c|}{ 2009-2010 } \\
\hline 1,0000 & \multicolumn{2}{|c|}{1,2046} & \multicolumn{2}{|c|}{2,0979} & \multicolumn{2}{|c|}{2,1396} \\
\hline
\end{tabular}

Fuente: elaboración propia en base a la encuesta CEDOP. $\mathrm{O}=$ origen, $\mathrm{D}=$ destino, $\mathrm{P}=$ periodo.

Señala Jorrat (2011a) que el modelo de fluidez constante tendía a exhibir una fuerte estabilidad a través de las cohortes entre orígenes y destinos. Por ello, Powers y Xie (1992) plantean un modelo log-multiplicativo de efectos de niveles (log-multiplicative layer effect model), conocido como modelo de diferencias uniformes (unidiff en la denominación de Erikson y Goldthorpe, 1992), que considera no solo la existencia de un patrón común, sino también de coeficientes de asociación de variables que darían cuenta de la intensidad de la fluidez (Fachelli y López Roldán, 2012b: 28). Supone entonces que todas las razones de oportunidades se mueven en una misma dirección de un periodo al otro.

Por tanto, considerados los casos de todos los años en tanto origen y destino, podemos ver que ninguno de los dos modelos (tres, considerando la independencia entre origen y destino en cada uno de los periodos), produce un buen ajuste si se considera su significación estadística. Atendiendo a otros indicadores menos «estrictos» en términos estadísticos, el modelo de fluidez constante mejora en un $82 \%$ al de independencia condicional, mientras que el de efecto uniforme solo lo hace en un 68\%. Lo relevante del caso es que es no puede sostenerse que, entre 1995 y 2009, se haya mantenido estable el patrón de movilidad social intergeneracional, lo cual es consecuente con el análisis que hemos realizado hasta el momento.

Ahora bien, si no puede mantenerse estable, ¿en qué sentido cambió? Para descubrirlo, deben analizarse los parámetros del modelo de efecto multiplicativo uniforme para cada periodo ${ }^{18}$. Todos los periodos subsiguientes a 1995 adquieren valores superiores a 1, en particular en el año 2007 se duplica, lo cual estaría visualizando que, entre la población ocupada, existen menores probabilidades relativas de tránsito entre las clases sociales.

18. Para hacerlo, se sitúa en 1 el parámetro del periodo «más lejano en el tiempo» y se compara con los subsiguientes. Si son menores que 1, la asociación entre orígenes y destinos será más débil y, si son mayores, ello indica que es más intensa que en el primer periodo (Jorrat, 2011a: 32). 
Ahora bien, como menciona Jorrat (2011a: 59), el análisis de estos modelos puede ser muy poderoso para detectar tendencias dominantes en los datos, pero es, a la vez, «algo crudo» para describir con precisión los cambios que han ocurrido. Es en este sentido que el análisis de las probabilidades relativas (razones de momios) nos ha permitido ver en una forma aún mucho más explícita la distribución desigual de oportunidades: las probabilidades relativas de cruce de la frontera entre «manual» $\mathrm{y}$ "no manual» han ido disminuyendo paulatinamente en el desarrollo del período, a su vez, las probabilidades de acceso a la clase media-alta también se han ido atenuando. Sin embargo, en los últimos años, se evidencia una tendencia a una mayor fluidez entre la clase trabajadora calificada y la clase media rutinaria, lo que estaría indicando que no todos los movimientos transitan en el mismo sentido.

\section{Movilidad y reproducción. Dos décadas complejas}

Habiendo hecho un ejercicio de análisis estadístico de las tasas de movilidad absoluta y relativa desde la mirada intergeneracional, nos encontramos con un panorama complejo. En primer lugar, el análisis de movilidad relativa arroja resultados disímiles con el de movilidad absoluta, pero, ¿qué significa esto? Según Cortés y Escobar Latapí (2005), las oportunidades de movilidad absoluta están fuertemente influidas por los cambios económicos, mientras que las relativas establecen la desigualdad con respecto a otras clases de ocupar tal o cual posición en la estructura social, independientemente del desempeño económico.

Entre la década de 1990 y finales del año 2000, las tasas absolutas de movilidad social disminuyeron, es decir que menos personas ocuparon una posición de clase diferenciada a la que tenía su hogar de origen. En particular, se detectó una fuerte tendencia a la reproducción de la clase trabajadora de mayor calificación, con un reclutamiento en la misma clase, muy fuerte hacia el final del periodo, distinguiéndose de la década de 1990, durante la cual había tenido un papel distribuidor por todas las clases sociales (efecto, como ya dijimos, del proceso de apertura, descentralización, desindustrialización y flexibilización de la economía). Asimismo, en términos de movilidad absoluta, la clase media de menor calificación fue una especie de "distribuidora» de posiciones hacia las clases medias más altas y, en menor proporción, hacia la clase trabajadora, pero, además, la clase media de rutina perdió su estatus, en términos de las recompensas recibidas (Kessler y Espinoza, 2007).

Por otro lado, en los extremos de la estructura social, se observa una tendencia a que el reclutamiento de las posiciones más ventajosas y más desacomodadas se dé entre las mismas clases o entre clases aledañas, tendencia que se hace más fuerte hacia fines de la década de 2000, en particular, una mayor reproducción de la clase trabajadora calificada, probablemente como efecto de un mayor dinamismo de la economía en las ramas tales como industria, logística y construcción, de la mano de una mayor recuperación de la demanda agregada de empleo (CIFRA-CTA, 2011; Acosta, 2010). 
Esta primera mirada permitiría sintetizar que las hipótesis tradicionales de movilidad social, de zona de contención y de cierre social o barrera de clase podrían estar reflejando cada vez de mejor manera la estructura de clases de la Región Metropolitana de Buenos Aires.

Ahora bien, para realizar dicha afirmación, es necesario indagar en el patrón endógeno de movilidad desde un análisis relativo que permite interpretar la probabilidad de ocupar uno u otro espacio de la estructura social considerando los diversos orígenes sociales en la comparación. Al hacer dicho análisis por medio de diferentes pruebas y técnicas estadísticas, observamos que el patrón de estratificación no se mantuvo estable, por el contrario, hubo una tendencia hacia una mayor rigidización: aun sin tomar en cuenta que las estructuras ocupacionales o la demanda de empleo, es decir, el patrón de fluidez, cambian, la sociedad se hace más desigual en términos de probabilidades de acceso. Los herederos de la clase trabajadora tienen menos oportunidades relativas de acceder a las clases medias, y estas últimas de descender. Dicha tendencia, que se cristalizó entre 1995 y 2009-2010, no implica, no obstante, que las clases sociales sean lo mismo hoy que hace quince años, puesto que los espacios sociales varían.

El análisis realizado en las últimas líneas nos permite sostener que, para el caso de la RMBA, no hay un régimen de mayor fluidez entre la década de 1990 y la actual, sino que, por el contrario, el régimen de movilidad se ha vuelto cada vez más rígido, encontrando solo algunas excepciones. A pesar de una tasa de movilidad social absoluta alta y de una preeminencia de la movilidad ascendente, la misma se ha debido a cambios estructurales, pero no a una mayor fluidez del régimen de clases. Comparativa y relativamente (como diría Carabaña [1999] en términos de justicia social), la estructura de clases, en tanto trayectorias intergeneracionales, se ha vuelto más rígida en los últimos quince años.

El análisis presentado solamente permitió caracterizar a las tendencias de movilidad social, en tanto relación entre origen social y posición de clase de los encuestados. Se realizó desde dos perspectivas: la de la movilidad social absoluta y la de la movilidad social relativa. Así pues, hemos podido observar el modo en que cada una de ellas ilumina sobre un aspecto de la realidad social y permite abrir la imaginación sociológica a pensar nuevos interrogantes. Desde una perspectiva alternativa a los supuestos teóricos, epistémicos y políticos del funcionalismo, esos interrogantes deberían estar centrados en comprender las formas que asumen los espacios sociales que conforman las diferentes trayectorias de origen y destino. Entre tantas otras problemáticas que permitirán abordar los procesos de movilidad social desde una perspectiva más compleja y enriquecedora, nos podríamos preguntar: ¿Cuáles son los mecanismos de cohesión y distinción que priman en ellos? ¿De qué manera se articulan recompensas económicas y clase social? ¿Cómo se relacionan los procesos de estructuración de clases con las políticas sociales y los regímenes de bienestar? Ese es el desafío por venir. 


\section{Referencias bibliográficas}

Acosta, Silvio (2010). «Las PyMI argentinas en el escenario post convertibilidad». Boletín Informativo Techint, 332.

Arceo, Nicolás; Monsalvo, Ana Paula; Schorr, Martín y Wainer, Andrés (2008). Empleo y salarios en la Argentina: Una visión de largo plazo. Buenos Aires: Capital Intelectual. Claves para Todos.

Azpiazu, D. y Schorr, M. (2008). "Continuidades y rupturas en la industria argentina: Del modelo de los noventa a la posconvertibilidad. Reflexiones preliminares». Realidad Económica, 240.

Basualdo, Eduardo (2006). Estudios de Historia Económica Argentina: Desde mediados del siglo XX a la actualidad. Buenos Aires: Siglo XXI Editores / FLACSO.

BeCCARIA, Luis (1978). "Una contribución al estudio de la movilidad social en Argentina: Análisis de los resultados de una encuesta para el Gran Buenos Aires». Desarrollo Económico [en línea], 17, 593-618. <http://dx.doi.org/10.2307/3466410>.

Benza, Gabriela (2010). «Transformaciones en los niveles de movilidad ocupacional intergeneracional asociados a las clases medias de Buenos Aires». Congreso de la Asociación de Estudios Latinoamericanos. Toronto, Canadá.

Bertaux, D. (1994). "Genealogías sociales comentadas y comparadas: Una propuesta metodológica». Estudios sobre las Culturas Contemporáneas, 6 (17), 333-349.

BoAdo MarTínez, Marcelo (2008). La movilidad social en el Uruguay contemporáneo. Montevideo: IUPERJ, UCM, UdelaR, CSIC.

Bourdieu, P. (2002). «Condición de clase y posición de clase». Revista Colombiana de Sociología, 7 (1), 119-141.

Bresser Pereira, L. (1964). "The rise of middle class in Brazil». En: Horowitz, L. (ed.). Revolution in Brazil: Politics and society in a developing nation. Nueva York: Dutton \& Co. Inc.

Cachón Rodríguez, Lorenzo (1989). ¿Movilidad social o trayectorias de clase? Madrid: Siglo XXI Editores.

CARABAÑa, Jorge (1999). Dos estudios sobre movilidad social intergeneracional. Madrid: Visor.

CENDA (2010). La anatomía del nuevo patrón de crecimiento y la encrucijada actual: La economía argentina en el período 2002-2010. Centro de Estudios para el Desarrollo Argentino. Cara o Ceca.

Chaplin, D. (1968). «Peruvian social mobility: Revolutionary and developmental». Journal of Inter-American Studies [en línea], 10 (4). Miami, EE. UU. <http://dx.doi.org/10.2307/165316>.

Chávez Molina, Eduardo y Gutiérrez Ageitos, Pablo (2009). «Movilidad intergeneracional y marginalidad económica: Un estudio de caso en el Conurbano Bonaerense». Población de Buenos Aires: Revista Semestral de Datos y Estudios Sociodemográficos Urbanos, 6 (10). Buenos Aires: Dirección General de Estadística y Censos (DGEyC) del Gobierno de la Ciudad de Buenos Aires.

Chávez Molina, Eduardo; Pla, Jésica y Molina Derteano, Pablo (2011). «Entre la adscripción, la estructura y el logro: Determinantes de la movilidad social. Ministro Rivadavia, Sur del Gran Buenos Aires, 2008-2009». Lavboratorio: Revista de Estudios sobre Cambio Estructural y Desigualdad Social, XI (24).

CIFRA-CTA (2011). «El nuevo patrón de crecimiento: Argentina 2002-2010». Informe de Coyuntura $N^{\circ} 7$. Centro de Investigación y Formación de la República Argentina-CIFRA. 
Cortés, Fernando y Escobar Latapí, Agustín (2005). "Movilidad social intergeneracional en el México urbano». Revista de la CEPAL, 85.

Costa Pinto, E. (1956). "Social stratification in Brazil: A general survey of some recent changes». Third World Congress of Sociology. Amsterdam.

- (1959). «Estratificação social e desenvolvimento econômico». Boletim do Centro Latino-Americano de Pesquisas em Ciências Sociais, 2 (3). Río de Janeiro.

Dalle, Pablo (2009). Movilidad social intergeneracional de la clase trabajadora en el Área Metropolitana de Buenos Aires. Tesis de maestría. Maestría en Investigación. Facultad de Ciencias Sociales. Universidad de Buenos Aires. Inédito. Consultado en la biblioteca Norberto Rodríguez Bustamante.

- (2011a). La movilidad social intergeneracional desde la clase trabajadora: Un análisis macro y micro social de los canales de ascenso, reproducción y descenso en la estructura de clases. Universidad de Buenos Aires. Facultad de Ciencias Sociales. Tesis de doctorado en Ciencias Sociales. Inédito. Consultado en la biblioteca Norberto Rodríguez Bustamante.

- (2011b). «Movilidad social intergeneracional desde y al interior de la clase trabajadora en una época de transformación estructural (AMBA: 1960-2005)». Lavboratorio: Revista de Estudios sobre Cambio Estructural y Desigualdad Social, XI (24). ISSN: $1515-6370$.

- (2012). «Cambios recientes en la estratificación social en Argentina (2003-2011): Inflexiones y dinámicas emergentes de movilidad social». Argumentos: Revista de Critica Social, 14.

Damill, M. y Frenkel. R. (2006). «El mercado de trabajo argentino en la globalización financiera». Revista de la CEPAL, 88. Santiago de Chile: CEPAL.

Danani, Claudia y Grassi, Estela (2009). "Con la mira en el trabajo». En: Grassi, Estela y DANANI, Claudia (organizadoras). El mundo del trabajo y los caminos de la vida. Buenos Aires: Espacio Editorial.

Danani, Claudia y Hintze, Susana (2011a). «Reformas y contra-reformas de la protección social: La seguridad social en la Argentina en la primera década del siglo». Revista Reflexión Política, 24 (12). Universidad Autónoma de Bucaramanga, Colombia, 18 a 29.

- (2011b). «Protección y seguridad social para distintas categorías de trabajadores: Definiciones conceptuales, propuestas de abordaje e intento de interpretación». En: Danani, Claudia y Hintze, Susana (coord.). Protecciones y desprotecciones: La seguridad social en la Argentina 1990-2010. 1a ed. Los Polvorines: Universidad Nacional de General Sarmiento.

Davis, K. y Moore, W.E. (1945). «Some principles of stratification». American Sociological Review [en línea], 242-249. <http://dx.doi.org/10.2307/2085643>.

ECheverría Zabalza, Javier (1999). La movilidad social en España. Madrid: ISTMO.

Erikson, Robert y Goldthorpe, John (1992). The Constant Flux: A Study of Class Mobility in Industrial Societies [en línea]. Oxford: Oxford University Press. $<$ http://dx.doi.org/10.2307/2579793>.

Espinoza, Vicente (2002). «La movilidad ocupacional en el Cono Sur». Proposiciones [en línea], 34. Santiago de Chile: Ediciones SUR. <http://dx.doi.org/10.5354/0716-632x.2006.27534>.

FACHELli, Sandra (2009). Nuevo modelo de estratificación social y nuevo instrumento para su medición: El caso argentino. Universitat Autònoma de Barcelona. Departament de Sociologia. Tesis de doctorado. 
Fachelli, Sandra y López Roldán, Pedro (2012a). Análisis de la movilidad social. Bellaterra: Universitat Autònoma de Barcelona.

- (2012b). "Two models of social stratification: From a classification scheme to a typology». The Second ISA Forum of Sociology "Social justice and democratization». Buenos Aires, Argentina.

Feito Alonso, Rafael (1995). Estructura social contemporánea: Las clases sociales en los paises industrializados. Madrid: Siglo XXI Editores.

Filgueira, Carlos y Geneletti, Carlo (1981). Estratificación y movilidad ocupacional en América Latina. Santiago de Chile: CEPAL. Cuadernos de la CEPAL, 39.

Franco, Rolando; León, Arturo y Atria, Raúl (2007). «Estratificación y movilidad social en América Latina: Una agenda de trabajo». En: Franco, Rolando; León, Arturo y Atria, Raúl (coords.). Estratificación y movilidad social en América Latina: Transformaciones estructurales de un cuarto de siglo. Santiago: LOM-CEPAL-GTZ.

Gerchunoff, Pablo y Torre, Juan Carlos (1996). «La política de liberalización económica en la administración de Menem». Desarrollo Económico [en línea], 143. Buenos Aires, Argentina.

<http://dx.doi.org/10.2307/3467293>.

Germani, G. (1961). «Estrategia para estimular la movilidad social». Desarrollo Económico, 1 (3), 59-96. <http://dx.doi.org/10.2307/3465803>.

- (1963a). Clase social subjetiva e indicadores objetivos de estratificación. Buenos Aires: Instituto de Sociología. Departamento de Sociología. Facultad de Filosofía y Letras. Universidad de Buenos Aires. Trabajos e Investigaciones del Instituto de Sociología. Colección Datos.

- (1963b). «La movilidad social en Argentina». En: Lipset, S. y Bendix, R. Movilidad social en la sociedad industrial. Buenos Aires: Editorial Universitaria de Buenos Aires.

- (1970). La estratificación social y su evolución histórica en la Argentina. Mimeo.

- (1987). Estructura social de la Argentina: Análisis estadístico [en línea]. Buenos Aires: Solar. <http://dx.doi.org/10.2307/1525275>.

Germani, G.; Germani, A.A.; Mera, C. y Rebón, J. (2010). Gino Germani: la sociedad en cuestión: Antología comentada. Buenos Aires: Consejo Latinoamericano de Ciencias Sociales (CLACSO).

Giddens, Anthony (1979). La estructura de las clases en las sociedades avanzadas [en línea]. Madrid: Alianza. <http://dx.doi.org/10.2307/40182812>.

GLass, D.V. (1954). Social Mobility in Britain [en línea]. Londres: Routledge \& Kegan Paul. <http://dx.doi.org/10.2307/1524957>.

GoldTHORPE, John (1987). Social mobility and class structure in modern Britain [en línea]. Oxford: Clarendon Press. <http://dx.doi.org/10.2307/589768>.

Gómez Rojas, Gabriela y Riveiro, Manuel (2013a). «Distintas maneras de medir la movilidad social de las mujeres en la Argentina contemporánea». Seminario Internacional sobre Desigualdad y Movilidad Social en América Latina. Mendoza.

- (2013b). «Exploraciones en torno a dos formas de medir la movilidad intergeneracional de las mujeres en la Argentina contemporánea». XXIX Congreso Latinoamericano de Sociología. Santiago de Chile. 
Goodman, L. (1965). "On statistical analysis of mobility tables». American Journal of Sociology [en línea], 70, mayo. Chicago: The University of Chicago Press. <http://dx.doi.org/10.1086/223932>.

Hutchinson, B. (1962). «Social Mobility rates in Buenos Aires, Montevideo and Sao Paulo: A preliminary comparison». Revista América Latina, 5.

INDEC (2003). ¿Qué es el gran Buenos Aires? Buenos Aires: Instituto Nacional de Estadísticas y Censos.

Ipola, Emilio de y Torrado, Susana (1976). Teoría y método para el estudio de la estructura de clases sociales. Santiago de Chile: Programa de Actividades Conjuntas ELAS-CELADE (PROELCE). Facultad Latinoamericana de Ciencias Sociales (FLACSO).

JorRAT, Jorge Raúl (1987). «Exploraciones sobre movilidad ocupacional intergeneracional masculina en el Gran Buenos Aires». Desarrollo Económico [en línea], 27, 261-278. <http://dx.doi.org/10.2307/3466982>.

- (1997). «En la huella de los padres: Movilidad ocupacional en el Buenos Aires de 1980». Desarrollo Económico [en línea], 37, 91-116. $<$ http://dx.doi.org/10.2307/3467154>.

- (2000). Estratificación social y movilidad: Un estudio del área metropolitana de Buenos Aires. Tucumán: Universidad Nacional de Tucumán.

- (2005). «Aspectos descriptivos de la movilidad intergeneracional de clase en Argentina: 2003-2004». Revista de Estudios sobre Cambio Social, VI (17-18), otoño-invierno. Instituto de Investigaciones Gino Germani. Facultad de Ciencias Sociales. Universidad de Buenos Aires (Argentina).

- (2007). «Movilidad intergeneracional de clase en Argentina 2002-2005». XXVI Congreso de ALAS. Guadalajara, México, del 13 al 18 de agosto.

- (2008). «Exploraciones sobre movilidad de clases en Argentina: 2003-2004». Documentos de Trabajo, 52. Buenos Aires: Instituto de Investigaciones Gino Germani. Facultad de Ciencias Sociales. Universidad de Buenos Aires.

- (2011a). «Diferencias de acceso a la educación en Argentina: 2003-2007». Lavboratorio: Revista de Estudios sobre Cambio Estructural y Desigualdad Social, 24. Mar del Plata: Ediciones Suárez.

- (2011b). «Clase, identidad de clase y percepción de las sociedades desde elitistas a igualitarias: Un estudio comparativo internacional». En: Movilidad y cambio social en América Latina. Buenos Aires: Instituto de Investigaciones Gino Germani. CDROM.

Kessler, Gabriel (2011). «Exclusión social y desigualdad, ¿nociones útiles para pensar la estructura social argentina?». Lavboratorio: Revista de Estudios sobre Cambio Estructural y Desigualdad Social, 24. Mar del Plata: Ediciones Suárez.

Kessler, G. y Espinoza, V. (2007). «Movilidad social y trayectorias ocupacionales en Buenos Aires: Continuidades, rupturas y paradojas». En: Franco, Rolando; León, Arturo y Atria, Raúl (coords.). Estratificación y movilidad social en América Latina: Transformaciones estructurales de un cuarto de siglo. Santiago: LOM-CEPAL-GTZ.

Kosacoff, Bernardo (2010). «Marchas y contramarchas de la industria argentina (1958-2008)». Documento de proyecto de la CEPAL.

Labbens, J. y Solari, A. (1966). «Movilidad social en Montevideo». En: Solari, A. Estudios sobre la estructura social uruguaya. Montevideo: Arca.

Lavopa, A. (2007). «La Argentina posdevaluación: ¿Un nuevo modelo económico?». Realidad Económica, 231, 48-74. Buenos Aires. 
- (2008). «Crecimiento económico y desarrollo en el marco de estructuras productivas heterogéneas: El caso argentino durante el período 1991-2006». En: LindeNвогм, J. (comp.). Trabajo, ingresos y politicas en Argentina: Contribuciones para pensar el siglo XXI. Buenos Aires: EUDEBA.

Lipset, S. y Bendix, R. (1963). Movilidad social en la sociedad industrial. Buenos Aires: Editorial Universitaria de Buenos Aires.

LlaCH, Juan (1997). Otro siglo, otra Argentina. Buenos Aires: Ariel.

Longhi, Augusto (2005). «La teorización de las clases sociales». Revista de Ciencias Sociales. Departamento de Sociología, XVIII (22), 104-114.

Molina Derteano, Pablo (2013). «Las muestras: Sobre la selección de casos para los estudios de estratificación y movilidad social en la Argentina». En: CHÁvez Molina, Eduardo (comp.); Pla, Jésica (colab.). Desigualdad y movilidad social en el mundo contemporáneo. Aportes empiricos y conceptuales: Argentina, China, España y Francia. Buenos Aires: Imago Mundi.

Palomino, Héctor (2007). «La instalación de un nuevo régimen de empleo en Argentina: De la precarización a la regulación». Revista Latinoamericana de Estudios del Trabajo (RELET), 12 (19), 121-144.

Panigo, D. y Neffa, J.C. (2009). «El mercado de trabajo argentino en el nuevo modelo de desarrollo». Dirección Nacional de Programación Macroeconómica. Buenos Aires: Ministerio de Economía y Finanzas Públicas.

Parsons, T. (1954). Ensayos de teoría sociológica. Buenos Aires: Paidós.

PÉrez, Pablo (2011). "Jóvenes, estratificación social y oportunidades laborales». Lavboratorio: Revista de Estudios sobre Cambio Estructural y Desigualdad Social, 24. Mar del Plata: Ediciones Suárez.

Pla, J. (2013a). Trayectorias inter generacionales de clase y marcos de certidumbre social: La desigualdad social desde la perspectiva de la movilidad. Región Metropolitana de Buenos Aires. 2003-2011. Tesis para optar por el título de doctora en Ciencias Sociales. Facultad de Ciencias Sociales. Universidad de Buenos Aires. Inédita.

- (2013b). «Reflexiones sobre el uso del concepto de clase para el estudio de la movilidad social». En: Chávez Molina, Eduardo (comp.); Pla, Jésica (colab.). Desigualdad y movilidad social en el mundo contemporáneo: Aportes empiricos y conceptuales. Argentina, China, España y Francia. Buenos Aires: Imago Mundi.

Pla, Jésica y Chávez Molina, Eduardo (2010a). «Mobility or social reproduction in a poor quarter of Buenos Aires». 2010 Spring Meeting of the Research Committee on Social Stratification and Mobility (RC28) of the International Sociological Association. Haifa, Israel, del 9 al 12 de mayo de 2010.

- (2010b). «Determinantes de la movilidad social de un barrio periférico del Gran Buenos Aires». II Encuentro Internacional sobre Teoría y Práctica Política en América Latina: Nuevas derechas e izquierdas en el escenario regional, del 3 al 5 de marzo de 2010. Facultad de Humanidades. Universidad Nacional de Mar del Plata. CD-ROM.

Pla, Jésica y Rodríguez de la Fuente, José (2013). «¿Cierre social, zona de amortiguamiento o fluidez?: Hipótesis sobre los patrones de movilidad social en un contexto de crecimiento económico e incremento de la capacidad regulatoria del Estado. Argentina 2007». En: Chávez Molina, Eduardo (comp.); Pla, Jésica (colab.). Desigualdad y movilidad social en el mundo contemporáneo: Aportes empíricos y conceptuales. Argentina, China, España y Francia. Buenos Aires: Imago Mundi.

Postone, Moishe (2006). Tiempo, trabajo y dominación social, una reinterpretación de la teoría crítica de Marx. Madrid: Marcial Pons Ediciones. 
Powers, Daniel y XIE, Yu (1992). Statistical methods for categorical data analysis. Estados Unidos: Emerald Group Pub Ltd.

Pucciarelli, Alfredo (2004). «La patria contratista: El nuevo discurso liberal de la dictadura militar encubre una vieja práctica corporativa». En: Pucciarelli, Alfredo (coord.). Empresarios tecnócratas y militares. Buenos Aires: Siglo XXI Editores.

Raczynski, D. (1971). Posición socioeconómica y consistencia de status de las ocupaciones. Santiago de Chile: Editorial del Pacífico.

- (1974). «La estratificación ocupacional en Chile». En: Los actores de la realidad Chilena. Santiago de Chile: Editorial del Pacífico.

Rubinstein, Juan Carlos (1973). Movilidad social en una sociedad dependiente. Buenos Aires: Corregidor.

SACCO, Nicolás (2011a). «Estructura y movilidad social en la Argentina: Evidencias a partir de la Encuesta Permanente de Hogares (2003-2010)». IX Jornadas de Sociologia: "Capitalismo del siglo XXI, crisis y reconfiguraciones: Luces y sombras en América Latina", del 8 al 12 de agosto de 2011. Universidad de Buenos Aires.

- (2011b). «Notas metodológicas a la Reconstrucción del Nomenclador de Condición Socio-Ocupacional». CT N. ${ }^{\circ}$ 4: Pobreza, Movilidad social y distribución del Ingreso: cambios en la estructura social de la última década en Argentina en general y la Provincia de Buenos Aires en particular del 2. ${ }^{\circ}$ Congreso de Sociólogos de la Provincia de Buenos Aires. Encuentro Internacional «Socializar la sociología». Mar del Plata, 6, 7 y 8 de octubre de 2011.

Salvia, Agustín y Quartulli, Diego (2011). «La movilidad y la estratificación social en la Argentina: Algo más que un sistema en aparente equilibrio». En: Lavboratorio: Revista de Estudios sobre Cambio Estructural y Desigualdad Social, 24. Mar del Plata: Ediciones Suárez.

SCHVARZER, Jorge (1977). «El régimen de regulación salarial en la Argentina moderna: Aproximación a sus condiciones globales». CISEA: Centro de Investigación de la Situación del Estado Administrativo. Buenos Aires, 50.

Solari, A. (1956). «Las clases sociales y su gravitación en la estructura política y social del Uruguay». Revista Mexicana de Sociología [en línea], 18 (2). México. <http://dx.doi.org/10.2307/3537811>.

Sorokin, Pitirim (1925). «Segunda parte. Movilidad social. Capitulo VII: Movilidad social, sus formas y fluctuación». Revista Mexicana de Sociología [en línea], 2. ${ }^{\text {a }}$ ed., 16 (2), mayo-agosto de 1954, 279-310. Universidad Nacional Autónoma de México. <http://dx.doi.org/10.2307/3537540>.

Torrado, Susana (1992). Estructura social de Argentina. 1945-1983. Buenos Aires: Ediciones de la Flor.

- (1998). «La medición empírica de las clases sociales». En: Torrado, Susana. Familia y diferenciación social: Cuestiones de métodos. Buenos Aires: EUDEBA.

Wright, Erik Olin (1994). Clases. Madrid: Siglo XXI Editores.

YASudA, S. (1964). "A methodological inquiry into social mobility». American Sociological Review [en línea], 29, 16-23.

<http://dx.doi.org/10.2307/2094637>. 


\section{Anexo}

Cuadro 7. Tabla de movilidad. Datos absolutos y residuos tipificados. RMBA. 1995

\begin{tabular}{|c|c|c|c|c|c|c|}
\hline \multirow[b]{2}{*}{ Clase del PSHO } & \multicolumn{6}{|c|}{ Clase del encuestado } \\
\hline & I. Clase media alta & II. Clase media & $\begin{array}{l}\text { III. Clase media } \\
\text { rutinaria }\end{array}$ & $\begin{array}{l}\text { IV. Clase } \\
\text { trabajadora } \\
\text { calificada }\end{array}$ & $\begin{array}{l}\text { V. Clase } \\
\text { trabajadora } \\
\text { marginal }\end{array}$ & Total \\
\hline Recuento & 79 & 46 & 31 & 43 & 18 & 217 \\
\hline Residuo tipificado & 3,3 & 1,3 & $-0,8$ & $-2,1$ & $-2,1$ & \\
\hline II Recuento & 15 & 19 & 16 & 6 & 1 & 57 \\
\hline Residuo tipificado & 0,2 & 2,8 & 2,1 & $-2,4$ & $-2,4$ & \\
\hline III Recuento & 30 & 24 & 17 & 18 & 4 & 93 \\
\hline Residuo tipificado & 1,4 & 1,9 & 0,4 & $-1,5$ & $-2,4$ & \\
\hline IV Recuento & 79 & 53 & 69 & 139 & 61 & 401 \\
\hline Residuo tipificado & $-2,1$ & $-2,1$ & 0,3 & 2,8 & 1,0 & \\
\hline V Recuento & 13 & 10 & 10 & 29 & 32 & 94 \\
\hline Residuo tipificado & $-2,2$ & $-1,6$ & $-1,4$ & 0,7 & 5,4 & \\
\hline Total & 216 & 152 & 143 & 235 & 116 & 862 \\
\hline \multicolumn{7}{|l|}{$X^{2}: 117,33$ Sig.: 0.000} \\
\hline
\end{tabular}

Base: encuestados ocupados entre 25 y 65 años $(n=862)$.

Fuente: elaboración propia en base a la encuesta CEDOP.

Cuadro 8. Tabla de movilidad. Datos absolutos y residuos tipificados. RMBA. 2003-2004

\begin{tabular}{|c|c|c|c|c|c|c|}
\hline \multirow[b]{2}{*}{ Clase del PSHO } & \multicolumn{6}{|c|}{ Clase del encuestado } \\
\hline & I. Clase media alta & II. Clase media & $\begin{array}{l}\text { III. Clase media } \\
\text { rutinaria }\end{array}$ & $\begin{array}{c}\text { IV. Clase } \\
\text { trabajadora } \\
\text { calificada }\end{array}$ & $\begin{array}{l}\text { V. Clase } \\
\text { trabajadora } \\
\text { marginal }\end{array}$ & Total \\
\hline I Recuento & 38 & 11 & 24 & 26 & 3 & 102 \\
\hline Residuo tipificado & 4,2 & $-0,2$ & 0,5 & $-1,5$ & $-3,0$ & \\
\hline II Recuento & 10 & 6 & 5 & 2 & 2 & 25 \\
\hline Residuo tipificado & 2,4 & 1,8 & $-0,1$ & $-2,2$ & $-0,8$ & \\
\hline III Recuento & 16 & 20 & 33 & 23 & 5 & 97 \\
\hline Residuo tipificado & $-0,6$ & 2,6 & 2,7 & $-1,8$ & $-2,3$ & \\
\hline IV Recuento & 34 & 26 & 45 & 112 & 49 & 266 \\
\hline Residuo tipificado & $-2,3$ & $-0,9$ & $-1,5$ & 2,2 & 2,0 & \\
\hline \multirow{3}{*}{$\begin{array}{l}\text { V Recuento } \\
\text { Residuo tipificado } \\
\text { Total }\end{array}$} & 12 & 4 & 16 & 35 & 21 & 88 \\
\hline & $-1,2$ & $-1,9$ & $-0,6$ & 0,9 & 2,5 & \\
\hline & 110 & 67 & 123 & 198 & 80 & 578 \\
\hline
\end{tabular}

Base: encuestados ocupados entre 25 y 65 años $(n=578)$.

Fuente: elaboración propia en base a la encuesta CEDOP. 
Cuadro 9. Tabla de movilidad. Datos absolutos y residuos tipificados. RMBA. 2007

\begin{tabular}{|c|c|c|c|c|c|c|}
\hline \multirow[b]{2}{*}{ Clase del PSHO } & \multicolumn{6}{|c|}{ Clase del encuestado } \\
\hline & I. Clase media alta & II. Clase media & $\begin{array}{l}\text { III. Clase media } \\
\text { rutinaria }\end{array}$ & $\begin{array}{l}\text { IV. Clase } \\
\text { trabajadora } \\
\text { calificada }\end{array}$ & $\begin{array}{l}\text { V. Clase } \\
\text { trabajadora } \\
\text { marginal }\end{array}$ & Total \\
\hline I Recuento & 53 & 14 & 20 & 11 & 5 & 103 \\
\hline Residuo tipificado & 31,9 & $-1,1$ & 1,3 & $-23,2$ & $-8,9$ & \\
\hline II Recuento & 11 & 6 & 3 & 3 & 2 & 25 \\
\hline Residuo tipificado & 5,9 & 2,3 & $-1,5$ & $-5,3$ & $-1,4$ & \\
\hline III Recuento & 38 & 26 & 32 & 22 & 8 & 126 \\
\hline Residuo tipificado & 12,2 & 7,5 & 9,2 & $-19,9$ & $-9,0$ & \\
\hline IV Recuento & 30 & 48 & 58 & 169 & 60 & 365 \\
\hline Residuo tipificado & $-44,9$ & $-5,5$ & $-8,1$ & 47,7 & 10,8 & \\
\hline V Recuento & 5 & 4 & 8 & 17 & 15 & 49 \\
\hline Residuo tipificado & $-5,0$ & $-3,2$ & $-0,9$ & 0,7 & 8,4 & \\
\hline Total & 137 & 98 & 121 & 222 & 90 & 668 \\
\hline \multicolumn{7}{|l|}{$X^{2}: 137,38$ Sig.: 0.000} \\
\hline
\end{tabular}

Base: encuestados ocupados entre 25 y 65 años $(n=668)$.

Fuente: elaboración propia en base a la encuesta CEDOP.

Cuadro 10. Tabla de movilidad. Datos absolutos y residuos tipificados. RMBA. 2009-2010

\begin{tabular}{|c|c|c|c|c|c|c|c|}
\hline \multirow{2}{*}{\multicolumn{2}{|c|}{ Clase del PSHO }} & \multicolumn{6}{|c|}{ Clase del encuestado } \\
\hline & & I. Clase media alta & II. Clase media & $\begin{array}{l}\text { III. Clase media } \\
\text { rutinaria }\end{array}$ & $\begin{array}{l}\text { IV. Clase } \\
\text { trabajadora } \\
\text { calificada }\end{array}$ & $\begin{array}{l}\text { V. Clase } \\
\text { trabajadora } \\
\text { marginal }\end{array}$ & Total \\
\hline \multirow[t]{2}{*}{ I } & Recuento & 20 & 8 & 5 & 11 & 2 & 46 \\
\hline & Residuo tipificado & 5,17 & 1,38 & $-1,33$ & $-1,79$ & $-1,81$ & \\
\hline \multirow{2}{*}{ II } & Recuento & 5 & 7 & 3 & 5 & 3 & 23 \\
\hline & Residuo tipificado & 0,92 & 2,89 & $-0,71$ & $-1,43$ & $-0,18$ & \\
\hline & Recuento & 13 & 11 & 16 & 15 & 3 & 58 \\
\hline & Residuo tipificado & 1,59 & 1,92 & 1,38 & $-1,78$ & $-1,86$ & \\
\hline & Recuento & 15 & 14 & 43 & 104 & 34 & 210 \\
\hline & Residuo tipificado & $-2,79$ & $-1,8$ & 0,3 & 1,99 & 0,65 & \\
\hline & Recuento & 1 & 0 & 6 & 17 & 12 & 36 \\
\hline & Residuo tipificado & $-1,84$ & $-1,96$ & $-0,39$ & 0,61 & 2,97 & \\
\hline \multirow{2}{*}{\multicolumn{2}{|c|}{$\begin{array}{l}\text { Total } \\
X^{2}: 95,48 \text { Sig.: } 0.000\end{array}$}} & 54 & 40 & 73 & 152 & 54 & 373 \\
\hline & & & & & & & \\
\hline
\end{tabular}

Base: encuestados ocupados entre 25 y 65 años $(n=373)$.

Fuente: elaboración propia en base a la encuesta CEDOP. 